\title{
Combined effects of dietary arginine, leucine and protein levels on fatty acid composition and gene expression in the muscle and subcutaneous adipose tissue of crossbred pigs
}

\author{
Marta S. Madeira ${ }^{1} \dagger$, Virgínia M. R. Pires ${ }^{1} \dagger$, Cristina M. Alfaia ${ }^{1}$, Richard Luxton ${ }^{2}$, Olena Doran ${ }^{2}$, \\ Rui J. B. Bessa ${ }^{1,3}$ and José A. M. Prates ${ }^{1 *}$ \\ ${ }^{1}$ CIISA, Faculdade de Medicina Veterinária, Universidade de Lisboa, Avenida da Universidade Técnica, Alto da Ajuda, \\ Lisboa 1300-477, Portugal \\ ${ }^{2}$ Faculty of Health and Life Sciences, Centre for Research in Biosciences, University of the West of England, \\ Coldharbour Lane, Bristol BS16 1QY, UK \\ ${ }^{3}$ UIPA, Instituto Nacional de Investigação Agrária e Veterinária, Fonte Boa, Vale de, Santarém 2005-048, Portugal \\ (Submitted 11 September 2013 - Final revision received 11 November 2013 - Accepted 20 November 2013 - First published online 6 February 2014)
}

\section{Abstract}

The cumulative effects of dietary arginine, leucine and protein levels on fat content, fatty acid composition and mRNA levels of genes controlling lipid metabolism in pig longissimus lumborum muscle and subcutaneous adipose tissue (SAT) were investigated. The experiment was performed on fifty-four intact male pigs (Duroc $\times$ Pietrain $\times$ Large White $\times$ Landrace crossbred), with a live weight ranging from 59 to $92 \mathrm{~kg}$. The pigs were randomly assigned to one of six experimental treatments $(n 9)$. The treatments followed a $2 \times 3$ factorial arrangement, with two levels of arginine supplementation $(0 v .1 \%)$ and three levels of a basal diet (normal protein diet, NPD; reduced protein diet, RPD; reduced protein diet to achieve $2 \%$ of leucine, RPDL). The results showed that dietary arginine supplementation did not affect the intramuscular fat (IMF) content and back fat thickness, but increased the total fat in SAT. This effect was associated with an increase in fatty acid synthase $(F A S N)$ and stearoyl-CoA desaturase (SCD) mRNA levels in SAT, which suggests that arginine might be involved in the differential regulation of some key lipogenic genes in pig muscle and SAT. The increase in IMF content under the RPD, with or without leucine supplementation, was accompanied by increased FASN and SCD mRNA levels. Arginine supplementation did not influence the percentage of main fatty acids, while the RPD had a significant effect on fatty acid composition in both tissues. Leucine supplementation of RPD did not change IMF, total fat of SAT and back fat thickness, but increased 16:0 and 18:1cis-9 and decreased 18:2n-6 in muscle.

Key words: Pigs: Arginine: Leucine: Reduced protein diets: Intramuscular fat: Fatty acid composition: Lipid metabolism

Pork is the most consumed meat in European Union countries, with 22387604 tons of carcasses produced in $2011^{(1)}$. The genetic selection of commercial pig lines has reduced subcutaneous fat content with the concomitant decreasing of marbling or intramuscular fat (IMF). The carcass leanness varies between breeds and is generally higher in white European breeds (Large White and Landrace) when compared with Duroc crossbreeds ${ }^{(2)}$. IMF content is one of the key meat quality traits, and the sensory properties of pork are negatively affected when IMF is reduced below $2-2.5 \%{ }^{(3)}$. According to Daszkiewicz et al. ${ }^{(4)}$, about $84 \%$ of the carcasses from commercial pig genotypes have a longissimus lumborum muscle fat content below the level required for acceptable eating quality. Furthermore, not only fat content but also fatty acid composition of IMF plays an important role in meat quality, and an appropriate ratio of SFA, MUFA and PUFA should be maintained in order to assure superior eating quality and nutritional value of meat ${ }^{(5)}$. Therefore, production of pork with high amounts of IMF and a balanced fatty acid composition, without an increase in subcutaneous fat (improved fat partitioning), is one of the main pig industry goals.

Abbreviations: ACACA, acetyl-COA carboxylase; CDNA, complementary DNA; CEBPA, CCAAT/enhancer binding protein $\alpha$; CRAT, carnitine O-acetyltransferase; FABP4, fatty acid binding protein 4; FADS1, fatty acid desaturase 1; FADS2, fatty acid desaturase 2; FAME, fatty acid methyl esters; FASN, fatty acid synthase; IMF, intramuscular fat; LPL, lipoprotein lipase; MLXIPL, MLX-interacting protein-like; PPARG, PPAR $\gamma$; RPD, reduced protein diet; RPDL, reduced protein diet with $2 \%$ of leucine; RPLPO, ribosomal protein large P0; SAT, subcutaneous adipose tissue; SCD, stearoyl-CoA desaturase; SREBP1, sterol regulatory element-binding protein 1.

* Corresponding author: J. A. M. Prates, fax +351 213652895, email japrates@fmv.utl.pt

† Both authors contributed equally to this work. 
Some feeding strategies have been suggested to improve fat partitioning in pigs, mainly based on dietary amino acid supplementation and reduced protein diets (RPD). Arginine is a semi-essential amino acid that, in addition to playing multiple physiological functions in animals, enhances lipolysis through the expression of the key genes responsible for the activation of fatty acid oxidation, in a tissue-specific manner ${ }^{(6,7)}$. Previous research ${ }^{(8)}$ on growing-finishing pigs has suggested that dietary supplementation with arginine increases IMF, thus improving fat partitioning. This was thought to be due to the arginine-induced modulation of lipogenesis and lipolysis regulation in muscle (lipogenesis increased) and white adipose tissue (lipolysis increased) ${ }^{(7)}$. Furthermore, the essential amino acid leucine is known to play an important role in the control of protein synthesis and insulin release. It is the only amino acid in pigs that can be used exclusively for fat synthesis (ketogenic), and may be converted to acetyl-CoA for fatty acid synthesis in muscle tissue ${ }^{(9)}$. Some studies have suggested that the IMF of pork can be increased by feeding finishing pigs with high levels of leucine ${ }^{(10)}$ or high levels of leucine in combination with low levels of lysine ${ }^{(9)}$.

In addition to the supplementation of pig diets with arginine and leucine, the use of RPD for increasing the IMF content in pigs, with less effect on subcutaneous fat deposition, has also been described ${ }^{(11)}$. The mechanisms of the tissue-specific effects of RPD are not clear ${ }^{(5)}$. One of the possibilities is a dietary-stimulated increase in stearoyl-CoA desaturase (SCD) activity in pig muscle, but not in subcutaneous adipose tissue $(\mathrm{SAT})^{(11)}$. Our recent data ${ }^{(12)}$ suggested the existence of breed- and tissue-specific mechanisms of fat deposition in pigs. The results indicated that the RPD increased the IMF content in lean pig genotypes but not in fat ones, and that the effect of RPD on lipogenesis is tissue-specific and mediated via the up-regulation of lipogenic enzymes in muscle and adipose tissue.

In pigs, the white adipose tissue is the main site for de novo fatty acid biosynthesis and lipogenesis. In contrast, muscle is one of the tissues playing the main role in the metabolism of glucose and degradation of lipids ${ }^{(13)}$. It is known that the regulation of adipogenesis and lipogenesis is a complex process, and a range of the transcription factors play the key role in this regulation. These transcription factors include sterol regulatory element-binding protein 1 (SREBP1), CCAAT/enhancer binding protein $\alpha$ (CEBPA) and PPAR $\gamma$ $(\mathrm{PPARG})^{(14)}$. Furthermore, MLX-interacting protein-like (MLXIPL) is a critical glucose-responsive transcription factor that regulates lipogenic and glycolytic genes, highly controlled by the insulin-regulated glucose transporter GLUT4 in adipose tissue $^{(15)}$. Moreover, MLXIPL also regulates various enzymes involved in glycolysis and lipogenesis, such as acetyl-CoA carboxylase (ACACA) and fatty acid synthase (FASN) ${ }^{(16)}$. $\mathrm{ACACA}^{(17)}$ and $\mathrm{FASN}^{(18)}$ are the key lipogenic enzymes controlling the rates of SFA biosynthesis, and SCD catalyses the rate-limiting step of MUFA biosynthesis. Fatty acid desaturase 1 (FADS1), encoding for $\Delta 5$ desaturase, and fatty acid desaturase 2 (FADS2), encoding for $\Delta 6$ desaturase, are membrane-bound enzymes that catalyse the synthesis of PUFA $^{(19)}$. Furthermore, carnitine palmitoyltransferase 1
(CPT-1B) and carnitine O-acetyltransferase (CRAT) are the rate-limiting enzymes of lipid catabolism responsible for the transport of fatty acid esters from the cytosol to mitochondria for $\beta$-oxidation ${ }^{(14)}$. Lipoprotein lipase (LPL) is the rate-limiting enzyme for the conversion of chylomicrons and VLDL into chylomicron remnants and LDL in tissues. Therefore, LPL controls TAG partitioning between adipose tissue and muscle, thereby increasing fattening or providing energy in the form of fatty acids for muscle growth ${ }^{(20)}$. Finally, fatty acid binding protein 4 (FABP4) is responsible for fatty acid transport in the adipocytes ${ }^{(21)}$. However, despite a large amount of information regarding the links between gene expression, lipogenic enzyme activity and fat partitioning in pigs, it remains unclear whether and how these processes contribute to the dietary regulation of fat partitioning in pigs.

Recent results ${ }^{(12)}$ from our research group have strongly indicated that adipogenesis and lipogenesis are regulated differently in the muscle and SAT of commercial crossbred pigs. In addition, it has been shown that increased IMF promoted by RPD is very likely due to lysine limitation, and it is mediated via the up-regulation of the adipogenic transcription factor PPARG and the lipogenic enzyme SCD. Taking into account the above-mentioned factors, the aim of the present study was (1) to explore the potential cumulative effects of dietary arginine supplementation, RPD and RPD with leucine supplementation on fat partitioning and fatty acid composition in commercial crossbred pigs, and (2) to investigate whether the effects of arginine and leucine are mediated via tissuespecific expression of genes controlling lipid metabolism.

\section{Materials and methods}

\section{Animals and diets}

The present trial was conducted at the facilities of Unidade de Investigação em Produção Animal (Instituto de Investigação Agrária e Veterinária (UIPA-INIAV)), and all the experimental procedures involving animals were reviewed by the Ethics Commission of the Centro de Investigação Interdisciplinar em Sanidade Animal/Faculdade de Medicina Veterinária (CIISA/FMV) and approved by the Animal Care Committee of the National Veterinary Authority (Direcção-Geral de Veterinária), following the appropriated European Union guidelines (Directive 86/609/EEC). All the members of staff involved in the animal experiments hold licence for conducting experiments on live animals from the Portuguese Veterinary Services. A total of fifty-four commercial cross-bred (25\% Duroc, 25\% Pietrain, 25\% Large White and 25\% Landrace) entire male pigs with an initial body weight of 58.9 (SD 1.59) kg were used. The animals were fed a standard concentrate diet from weaning until the beginning of the experiment. All the animals were randomly assigned to one of the six diets in a $2 \times 3$ factorial arrangement (arginine treatment or an isonitrogenous control, and two protein levels with or without leucine addition).

The diets were isoenergetically formulated (14 MJ metabolisable energy $/ \mathrm{kg}$ ) and differed in crude protein, arginine and leucine contents as follows: $16.0 \%$ of crude protein (normal 
protein diet, NPD); $13.0 \%$ of crude protein (RPD); $13.0 \%$ of crude protein plus L-leucine in the diet to achieve $2 \%$ (reduced protein diet with leucine, RPDL). The arginine treatment and the isonitrogenous control were obtained through supplementation of the basal diets with $1.0 \%$ of L-arginine and $2.05 \%$ of L-alanine, respectively. Arginine or alanine was added to the basal diet at the expense of maize starch to obtain isoenergetic diets. The amino acids were obtained from $\mathrm{FH}$ Diedrichs \&
Ludwig Post. The ingredients, chemical composition and fatty acid profile of the experimental diets are shown in Table 1. The animals were housed in three pens of three pigs per each treatment $(n 9)$ ). During the experiment, the animals were fed individually twice per day and had access to water ad libitum. Feed offered and refusals were recorded daily in order to calculate feed intake. Pigs were weighed weekly, just before feeding, throughout the experiment.

Table 1. Ingredients and chemical, amino acid and fatty acid compositions of the experimental diets

\begin{tabular}{|c|c|c|c|c|c|c|}
\hline \multirow[b]{2}{*}{ Diets } & \multicolumn{3}{|c|}{ Control } & \multicolumn{3}{|c|}{ Arginine } \\
\hline & NPD & RPD & RPDL & NPD & RPD & RPDL \\
\hline \multicolumn{7}{|l|}{ Ingredients (\%) } \\
\hline Maize & 62.9 & $67 \cdot 3$ & $75 \cdot 0$ & 63.7 & $72 \cdot 3$ & $74 \cdot 5$ \\
\hline Barley & $10 \cdot 0$ & $15 \cdot 0$ & 8.00 & $10 \cdot 0$ & $10 \cdot 0$ & $10 \cdot 0$ \\
\hline Soyabean meal & $18 \cdot 9$ & 10.9 & 9.60 & $16 \cdot 3$ & $7 \cdot 80$ & $7 \cdot 2$ \\
\hline Sunflower meal & 1.64 & 0.44 & - & 4.56 & 4.66 & 1.98 \\
\hline Soyabean oil & $1 \cdot 15$ & 0.98 & 0.99 & 1.06 & 0.88 & 0.85 \\
\hline Calcium carbonate & 0.73 & 0.73 & 0.71 & 0.72 & 0.70 & 0.71 \\
\hline Bi-calcium phosphate & $1 \cdot 21$ & $1 \cdot 32$ & $1 \cdot 38$ & $1 \cdot 22$ & $1 \cdot 35$ & 1.39 \\
\hline Sodium bicarbonate & 0.11 & 0.01 & - & 0.14 & 0.06 & 0.07 \\
\hline Salt & 0.35 & 0.43 & 0.44 & 0.33 & 0.39 & 0.38 \\
\hline L-Lys & 0.30 & 0.12 & 0.17 & 0.34 & 0.17 & 0.21 \\
\hline L-Met & 0.06 & - & - & 0.06 & - & - \\
\hline L-Thr & 0.07 & - & - & 0.08 & - & - \\
\hline L-Ala & $2 \cdot 05$ & $2 \cdot 05$ & $2 \cdot 05$ & - & - & - \\
\hline L-Arg & - & - & - & 1.00 & $1 \cdot 00$ & $1 \cdot 00$ \\
\hline L-Leu & - & 0.17 & $1 \cdot 14$ & - & 0.17 & $1 \cdot 17$ \\
\hline Vitamin-trace mineral premix & 0.40 & 0.40 & 0.40 & 0.40 & 0.40 & 0.40 \\
\hline Acid mixture & 0.10 & 0.10 & 0.10 & 0.10 & 0.10 & $0 \cdot 10$ \\
\hline Antioxidant mixture & 0.005 & 0.005 & 0.005 & 0.005 & 0.005 & 0.005 \\
\hline \multicolumn{7}{|l|}{ Chemical composition (\% diet) } \\
\hline DM & $87 \cdot 5$ & $87 \cdot 7$ & $87 \cdot 8$ & $87 \cdot 7$ & $87 \cdot 7$ & $87 \cdot 9$ \\
\hline Crude protein & $16 \cdot 0$ & $13 \cdot 1$ & $13 \cdot 1$ & $15 \cdot 9$ & 12.9 & $12 \cdot 7$ \\
\hline Starch & $38 \cdot 3$ & $42 \cdot 6$ & 42.5 & 38.5 & $42 \cdot 5$ & $43 \cdot 1$ \\
\hline Crude fat & $3 \cdot 36$ & 3.46 & 3.54 & 3.46 & 3.46 & 3.56 \\
\hline Crude fibre & $4 \cdot 38$ & $3 \cdot 22$ & 3.06 & 4.66 & $4 \cdot 20$ & $3 \cdot 36$ \\
\hline Ash & 3.88 & 3.78 & 3.78 & $4 \cdot 16$ & 3.98 & 3.80 \\
\hline $\mathrm{Ca}$ & 0.66 & 0.73 & 0.75 & 0.59 & 0.68 & 0.71 \\
\hline $\mathrm{P}$ & 0.49 & 0.51 & 0.52 & 0.51 & 0.52 & 0.52 \\
\hline ME (MJ ME/kg) & $13 \cdot 8$ & $14 \cdot 1$ & $14 \cdot 3$ & $13 \cdot 9$ & $14 \cdot 1$ & $14 \cdot 3$ \\
\hline \multicolumn{7}{|l|}{ Amino acid composition ( $\%$ diet) } \\
\hline Ala & $3 \cdot 13$ & $3 \cdot 25$ & 3.52 & 0.16 & 0.51 & 0.33 \\
\hline Arg & 1.05 & 0.83 & 0.49 & 1.84 & $1 \cdot 60$ & 1.56 \\
\hline Asp & 0.49 & 0.35 & 0.31 & 0.45 & 0.38 & 0.30 \\
\hline Glu & $2 \cdot 07$ & 1.54 & $1 \cdot 38$ & $1 \cdot 82$ & 1.59 & $1 \cdot 34$ \\
\hline Gly & 0.43 & 0.35 & 0.41 & 0.63 & 0.43 & 0.41 \\
\hline His & $2 \cdot 02$ & $1 \cdot 21$ & 0.92 & $1 \cdot 27$ & 1.02 & 0.90 \\
\hline Ile & 0.45 & 0.32 & 0.38 & 0.50 & 0.35 & 0.35 \\
\hline Leu & 1.01 & 0.93 & 1.51 & 0.95 & 0.94 & 1.74 \\
\hline Lys & 0.84 & 0.47 & 0.45 & 0.70 & 0.43 & 0.43 \\
\hline Met & 0.02 & 0.04 & 0.07 & 0.06 & 0.18 & 0.10 \\
\hline Phe & 0.68 & 0.47 & 0.28 & 0.39 & 0.33 & 0.31 \\
\hline Pro & 0.83 & 0.79 & 0.61 & 0.85 & 0.96 & 0.89 \\
\hline Ser & 0.81 & 0.67 & 0.61 & 0.78 & 0.63 & 0.57 \\
\hline Thr & 0.17 & 0.10 & 0.12 & 0.20 & 0.19 & 0.18 \\
\hline Tyr & 0.31 & 0.20 & 0.18 & 0.24 & 0.17 & 0.13 \\
\hline Val & 0.70 & 0.56 & 0.44 & 0.57 & 0.47 & 0.45 \\
\hline \multicolumn{7}{|c|}{ Fatty acid composition (\% total fatty acids) } \\
\hline $16: 0$ & $15 \cdot 0$ & $15 \cdot 3$ & $14 \cdot 9$ & $15 \cdot 0$ & $15 \cdot 0$ & 14.9 \\
\hline $18: 0$ & $2 \cdot 72$ & 2.47 & 2.65 & 2.58 & 2.43 & $2 \cdot 38$ \\
\hline $18: 1$ cis-9 & $24 \cdot 9$ & $25 \cdot 0$ & $25 \cdot 8$ & 24.9 & $25 \cdot 4$ & $25 \cdot 6$ \\
\hline $18: 1$ cis-11 & 1.05 & 0.97 & 0.98 & $1 \cdot 01$ & 0.95 & 0.94 \\
\hline $18: 2 n-6$ & $53 \cdot 0$ & $53 \cdot 1$ & $52 \cdot 8$ & $53 \cdot 2$ & 53.4 & $53 \cdot 3$ \\
\hline $18: 3 n-3$ & 3.32 & $3 \cdot 10$ & $2 \cdot 85$ & $3 \cdot 22$ & 2.77 & 2.77 \\
\hline
\end{tabular}

NPD, normal protein diet; RPD, reduced protein diet; RPDL, reduced protein diet with leucine addition; ME, metabolisable energy. 


\section{Slaughter and sampling}

Feed was removed $17-19 \mathrm{~h}$ before the slaughter of animals. The pigs were slaughtered at an average live body weight of 91.7 (SD 1.61) kg, with no significant differences $(P>0.05)$ between animal groups, at the L-INIA Experimental Abattoir (INIAV). Immediately after electrical stunning and exsanguination, samples of longissimus lumborum muscle and SAT were collected from the right side of carcass at the first lumbar vertebral level for gene expression analysis. The samples were rinsed with sterile RNase-free cold saline solution, cut into small pieces (thickness of approximately $0.3 \mathrm{~cm}$ ), stabilised in RNA Later solution (Qiagen) and stored at $-80^{\circ} \mathrm{C}$ until analysed. For analysis of IMF and fatty acid composition, longissimus lumborum muscle and SAT samples were collected after slaughter from the right carcass side between the third and fifth lumbar vertebras. Muscle was collected and trimmed of visible connective and adipose tissues before blended in a food processor. The samples of muscle and SAT were vacuum packed and stored at $-20^{\circ} \mathrm{C}$ until analysed. Back fat thickness was measured in the left carcass side at the $\mathrm{P}_{2}$ (last rib position) location.

\section{Feed analysis}

Feed samples, collected five times during the trial (the first collection was in the beginning of the trial, followed by regular collections with a 3-week interval until the slaughter), were analysed for DM by drying a sample at $100^{\circ} \mathrm{C}$ to a constant weight. $\mathrm{N}$ content was determined by the Kjeldahl $\operatorname{method}^{(22)}$, and crude protein was calculated as $6.25 \times \mathrm{N}$. Crude fibre was determined by the procedure described by the Association of Official Analytical Chemists (AOAC) ${ }^{(22)}$. The samples were extracted with petroleum ether, using an automatic Soxhlet extractor (Gerhardt Analytical Systems), and crude fat was determined. Analysis of ash and starch contents was carried out according to the procedures described by the $\mathrm{AOAC}^{(22)}$ and Clegg ${ }^{(23)}$, respectively. Gross energy in the feed was determined by adiabatic bomb calorimetry (Parr 1261; Parr Instrument Company). Fatty acid methyl esters (FAME) of the feed samples were analysed by onestep extraction and transesterification, using heptadecaenoic acid $(17: 0)$ as the internal standard ${ }^{(24)}$. Total amino acids were extracted from the feed according to the method described by the $\mathrm{AOAC}^{(25)}$. The extract was analysed by HPLC (Agilent 1100; Agilent Technologies) to quantify total amino acids in the feed, following the procedure described by Henderson et al. ${ }^{(26)}$.

\section{Intramuscular fat and fatty acid composition}

The longissimus lumborum muscle and SAT samples were lyophilised $\left(-60^{\circ} \mathrm{C}\right.$ and $\left.2.0 \mathrm{hPa}\right)$ to constant weight using a lyophilisator (Edwards High Vacuum International), kept dry at $-20^{\circ} \mathrm{C}$ and analysed within 2 weeks. The total fat content of muscle samples (IMF) and SAT was determined using fresh samples by hydrolysis with $4 \mathrm{M}-\mathrm{HCl}$ followed by Soxhlet extraction for $6 \mathrm{~h}$ with petroleum ether ${ }^{(22)}$. For the fatty acid analysis of longissimus lumborum muscle and SAT samples, FAME were extracted from the lyophilised samples (approximately 250 and $50 \mathrm{mg}$, respectively), according to the Folch et $a{ }^{(27)}$ method, using dichloromethane-methanol (2:1, v/v) instead of chloroform-methanol $(2: 1, \mathrm{v} / \mathrm{v})$, as described by Carlson ${ }^{(28)}$. All the extraction solvents contained $0.01 \%$ butylated hydroxytoluene as an antioxidant. Fatty acids were converted to methyl esters by a combined transesterification procedure with $\mathrm{NaOH}$ in anhydrous methanol ( $0.5 \mathrm{M})$, followed by $\mathrm{HCl}-$ methanol $(1: 1, \mathrm{v} / \mathrm{v})$, at $50^{\circ} \mathrm{C}$ during 30 and 10 min, respectively, according to Raes et al. ${ }^{(29)}$.

Quantification of FAME in muscle and SAT was performed using a gas chromatograph HP7890A (Hewlett-Packard), equipped with a flame ionisation detector and a Supelco$\operatorname{wax}^{\text {TM }} 10$ capillary column $(30 \mathrm{~m} \times 0.20 \mathrm{~mm}$ inner diameter, $0 \cdot 20 \mu \mathrm{m}$ film thickness; Supelco). The column temperature of $150^{\circ} \mathrm{C}$ was held for $11 \mathrm{~min}$, then increased to $210^{\circ} \mathrm{C}$ at a rate of $3^{\circ} \mathrm{C} / \mathrm{min}$ and maintained for $30 \mathrm{~min}$. He gas was used as carrier at a flow rate of $1.3 \mathrm{ml} / \mathrm{min}$, the split ratio was $1: 20$ and $1 \mu \mathrm{l}$ of sample was injected. The injector and detector temperatures were 250 and $280^{\circ} \mathrm{C}$, respectively. The quantification of total FAME was done using nonadecanoic acid (19:0) as the internal standard. Results for each fatty acid are expressed as a percentage of the sum of detected fatty acids (\% total fatty acids).

\section{RNA isolation and complementary DNA synthesis}

Total RNA from SAT samples was isolated using the RNeasy lipid tissue mini kit (Qiagen). For the longissimus lumborum muscle samples, total RNA was isolated with TRIzol Reagent (Invitrogen) and purified with the RNeasy mini kit (Qiagen). All the procedures were performed in accordance with the manufacturer's protocols, and all RNA were subjected to an on-column DNase I (Qiagen) treatment to remove any contamination with genomic DNA. RNA concentration was determined by the analysis of absorbance $(A)$ at $260 \mathrm{~nm}$ using a NanoDrop ND-2000c spectrophotometer (Nanodrop; Thermo Fisher Scientific). The $A_{260 / 280}$ ratios were between $1 \cdot 9$ and $2 \cdot 1$, and RNA integrity was evaluated using electrophoresis with $1.5 \%$ agarose and ethidium bromide staining $(1 \cdot 25 \mathrm{ng} / \mu \mathrm{l}$; Sigma-Aldrich).

Total RNA $(1 \mu \mathrm{g})$ was reverse transcribed using the highcapacity complementary DNA (cDNA) reverse transcription kit, based on the use of both oligo(dT) and random hexamers as primers, following the manufacturer's protocol (Applied Biosystems) and as has been previously described by Madeira et $a l .^{(12)}$. Control reactions were carried out in the absence of RT in order to check for DNA contamination. cDNA quality was tested by end-point PCR, amplifying all housekeeping and target genes used in the present study. The cDNA obtained was divided into aliquots and stored at $-20^{\circ} \mathrm{C}$ until further analysis.

\section{Real-time quantitative PCR}

Genes used in the present study were selected based on their role in the transcriptional control of adipogenesis 


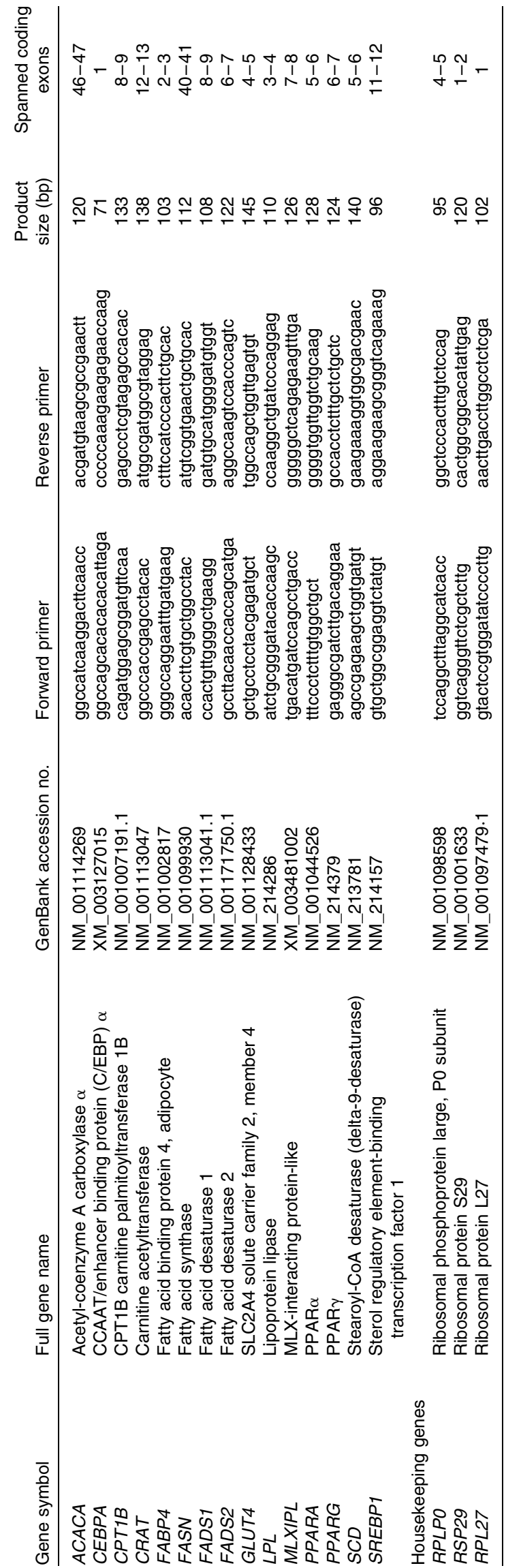

regulation/differentiation (MLXIPL, PPARG, SREBP1 and CEBPA), regulation of lipogenesis (ACACA, FASN, FADS1, $F A D S 2$ and $S C D)$, glucose uptake (GLUT4), fatty acid uptake ( $L P L)$ and lipid oxidation (CRAT, CPT1 and PPARA) (Table 2). Gene-specific intron-spanning primers were designed with the aid of Primer3 (http://frodo/wi.mit.edu/primer3/) and Primer Express 2.0 software (Applied Biosystems), based on Sus scrofa sequences (www.ncbi.nlm.nih.gov), to generate amplicons ranging in size from 71 to $145 \mathrm{bp}$. Sequence of primers, GenBank accession numbers, amplicon length and span exons for PCR products are provided in Table 2 . The primers were synthesised commercially by NZYTech. Sequence homology searches against the database of GenBank showed that these primers were specific to the sequence to which they were designed. In order to test the primers and verify the amplified products, a conventional PCR was carried out for all the genes investigated in the present study before performing the real-time quantitative PCR experiments. Briefly, genes were amplified by conventional qualitative PCR (using $1 \mu \mathrm{l}$ of cDNA) using the same primers designed for real-time PCR. PCR products were extracted from gels using QIAquick ${ }^{\circledR}$ Gel Extraction Kits (Qiagen). The fragments were then cloned into the pGEM $^{\circledR}$-Teasy cloning vector (Promega), transformed into pMOS Blue Escherichia coli and selected on Luria broth (LB)-agar plates containing ampicillin $(50 \mu \mathrm{g} / \mathrm{ml})$. Plasmids containing inserts of right size were sequenced by Stabvida, and homology searches were performed with Blast (www.ncbi.nlm.nih.gov/blast) to confirm the identity of amplified fragments. PCR efficiency was calculated for each amplicon, in triplicate, using the StepOnePlus PCR System software (Applied Biosystems), by amplifying 5-fold serial dilutions of pooled cDNA. All primer sets exhibited an efficiency ranging between 90 and $110 \%$, and correlation coefficients were higher than 0.99.

The gene expression profile of five candidate references genes (glyceraldehyde-3-phosphate dehydrogenase (GAPDH), 605 ribosomal protein L27 ( $R P L 27$ ), ornithine decarboxylase antizyme 1 (OAZ1), ribosomal protein large P0 (RPLPO) and $40 S$ ribosomal protein S29 (RPS29)) were analysed in twenty-four randomly selected different samples (four pigs from each group). The geNormlgorithm ${ }^{(30)}$ and NormFinder algorithm $^{(31)}$ were used to evaluated their stability in all the samples. RPLPO and RPS29 were identified as the most stable pair of endogenous control genes for the normalisation of results in longissimus lumborum muscle, whereas the RPLPO and RPL27 genes were identified as the most stable pair for SAT. Quantitative RT-PCR were carried out using MicroAmp Optical ninety-six-well plates (Applied Biosystems) in a StepOnePlus thermocycler (Applied Biosystems) in standard cycling conditions. Measurements of each sample for each gene were conducted in duplicate. Each $12.5 \mu$ l of PCR reaction mixtures contained $6.25 \mu \mathrm{l}$ of $2 \times$ Power SYBR Green PCR Master Mix (Applied Biosystems), $160 \mathrm{~nm}$ of gene-specific forward and reverse primers, and $2 \mu \mathrm{l}$ of diluted cDNA as a template. No transcription and no template samples were used as controls. A melting curve analysis was performed after the final cycle to ensure the specificity of the primer and the absence of primer-dimer formation. 
The relative amount of each target gene was calculated using the geometric mean of RPLPO/RPS29 and RPLPO/RPL27 as a normaliser for muscle and SAT, respectively. The relative gene expression levels were calculated using the Livak method $^{(32)}$, corrected for the variation in amplification efficiency, as described by Fleige et l $^{(33)}$.

\section{Statistical analysis}

All data were checked for normal distribution and variance homogeneity. As variance heterogeneity was detected for most fatty acids and genes, these data were analysed using Proc MIXED of the SAS software package ${ }^{(34)}$ (version 9.2; SAS Institute), with a model including dietary arginine and the basal diet (protein level with or without leucine supplementation) and their respective interaction, as fixed effects, and the repeated statement considering the group option to accommodate variance heterogeneity. As IMF, total fat of SAT and $\mathrm{P}_{2}$ had variance homogeneity, these data were analysed using the same model, but without the repeated statement. If the interaction between dietary arginine and protein level was significant, multiple comparisons of least-square means were determined using the PDIFF with Tukey-Kramer adjustment options of SAS. The contrasts between dietary protein level (NPD $v$. RPD, NPD $v$. RPDL and RPD $v$. RPDL) were performed. The level of significance was set at $P<0 \cdot 05$.

The need for covariate adjustment was explored using animal age, live and slaughter weights, IMF, total fat of SAT and $\mathrm{P}_{2}$ as covariates, but only IMF and total fat were found to be significant for several variables. Thus, IMF and total fat were retained as covariates for some muscle and SAT variables, respectively. For each variable, where the use of covariates was justified, the structure of the covariate model was determined according to the procedures described by Milliken $\&$ Johnson $^{(35)}$ and ranged from a simple slope model to individual slopes for each combination of the arginine $\times$ protein level. The adjusted variables and their covariance models are given in table footnotes.

Pearson's correlation matrices were computed using the PROC CORR of SAS. When needed, adjusted variables to the common mean IMF in muscle and the common mean total fat in SAT were used to compute Pearson's correlations.

\section{Results}

The present study discusses the results of the trial in commercial pigs regarding fat content and fatty acid composition in longissimus lumborum muscle and SAT. Furthermore, the possible molecular mechanisms underlying fat deposition in muscle and SAT were elucidated through the assessment of the mRNA expression level of genes encoding for key lipogenic enzymes and transcription factors. This experiment also generated the results on pigs' performance, carcass traits and sensory quality of meat that are not presented here (MS Madeira, CM Alfaia, P Costa, PA Lopes, JPC Lemos, RJB Bessa and JAM Prates, unpublished results). In brief, the results indicated that dietary arginine supplementation does not affect growth performance and pork quality traits, excluding a slight change in some sensory attributes. In addition, the data confirmed that low-protein diets decrease animal performance in lean pig genotypes. Dietary leucine supplementation of low-protein diets does not seem to have any additional effect on growth performance and meat quality traits. Finally, the data indicated that the cumulative effects of a low-protein diet, leucine and arginine, relative to the individual effect of the low-protein diet, result in increased pork tenderness and overall acceptability.

\section{Intramuscular fat and fatty acid composition of muscle}

The results of IMF, fatty acid composition and partial sums of fatty acids in the longissimus lumborum muscle are presented in Table 3. The IMF content was not affected either by dietary arginine $(P=0.274)$ or by leucine supplementation of RPD $(P=0.801)$. However, the reduction of protein level in the diet resulted in a significant $(P \leq 0.001)$ increase in IMF content by 45 and $48 \%$ for the RPD and RPDL groups, respectively.

The predominant fatty acids in IMF were 18:1cis-9 $(32-37 \%$ of total FAME), 16:0 (21-22\%), 18:2n-6 $(12-16 \%), 18: 0$ (11-12\%), 18:1cis-11 (4\%) and 20:4n-6 (3-4\%) for all the experimental groups. The term 'others' in Table 3 refers to unidentified minor fatty acids and to the 16:0, 18:0 and 18:1 plasmalogen-derived dimethylacetals. Arginine treatment affected only the percentage of three of the twenty-four fatty acids identified in the muscle $(12: 0$, 18:1cis-11 and $22: 5 n-3)$. The dietary protein or leucine levels affected the proportion of nineteen individual fatty acids in the muscle. The proportion of $12: 0,16: 1$ cis- 7 and $18: 3 n-3$ was lower in pigs fed the RPD and RPDL when compared with the animals fed the NPD. Contrarily, 18:1cis-11 was higher in the RPD and RPDL than in the NPD. The RPDL increased the proportion of $18: 1$ cis-9 and $20: 1$ cis-11 and decreased the proportion of $18: 2 n-6$, when compared with the NPD and RPD. The pigs fed the RPDL had lower proportions of $20: 3 n-6(P=0.008), 20: 4 n-6(P=0 \cdot 006), 20: 5 n-3$ $(P=0.006)$ and $22: 5 n-3(P=0 \cdot 031)$ than those fed the RPD.

Concerning the partial sums of fatty acids (Table 3 ), the RPD decreased the percentage of SFA $(P=0.006)$ when compared with the NPD. The proportion of MUFA was higher in the RPDL relative to the NPD and RPD. In contrast, PUFA and $n$-6 PUFA were lower in the RPDL when compared with the NPD and RPD. The PUFA:SFA ratio was lower in the RPD and RPDL when compared with the NPD, while a significant interaction between arginine supplementation and protein level $(P=0.031)$ was obtained for the $n-6: n-3$ ratio.

\section{Fatty acid content and composition of subcutaneous adipose tissue}

The results of back fat thickness at the $\mathrm{P}_{2}$ site, total fat and fatty acid composition for SAT are presented in Table 4. Dietary arginine supplementation did not affect $(P=0.720)$ back fat thickness at the $\mathrm{P}_{2}$ site. However, an increase of 18 and $21 \%$ of $\mathrm{P}_{2}$ back fat thickness was observed for pigs fed the RPD $(P=0.041)$ and RPDL $(P=0.021)$, respectively, when compared with those fed the NPD. The total fat of SAT of pigs fed arginine was $6 \%$ higher $(P=0 \cdot 020)$ when compared with those 
Table 3. Effect of dietary arginine (Arg), leucine and protein (Prot) levels on intramuscular fat (IMF; \% muscle), fatty acid composition (\% total fatty acids), partial sums of fatty acids and related ratios in the longissimus lumborum muscle of pigs

(Mean values with their standard errors)

\begin{tabular}{|c|c|c|c|c|c|c|c|c|c|c|c|c|c|c|c|c|c|}
\hline & \multicolumn{6}{|c|}{ Control } & \multicolumn{6}{|c|}{ Arginine } & \multicolumn{5}{|c|}{$P$} \\
\hline & \multicolumn{2}{|c|}{ NPD } & \multicolumn{2}{|c|}{ RPD } & \multicolumn{2}{|c|}{ RPDL } & \multicolumn{2}{|c|}{ NPD } & \multicolumn{2}{|c|}{ RPD } & \multicolumn{2}{|c|}{ RPDL } & \multicolumn{4}{|c|}{ Dietary protein level } & \multirow[b]{2}{*}{ Arg $\times$ Pro } \\
\hline & Mean & SE & Mean & SE & Mean & SE & Mean & SE & Mean & SE & Mean & SE & Arginine & $\begin{array}{c}\text { NPD } v \text {. } \\
\text { RPD }\end{array}$ & $\begin{array}{l}\text { NPD } v \text {. } \\
\text { RPDL }\end{array}$ & $\begin{array}{l}\text { RPD } v \text {. } \\
\text { RPDL }\end{array}$ & \\
\hline IMF & 1.34 & 0.181 & 1.85 & 0.181 & $2 \cdot 20$ & 0.181 & 1.53 & 0.181 & $2 \cdot 30$ & 0.181 & 2.05 & 0.181 & 0.274 & 0.001 & $<0.001$ & 0.801 & 0.780 \\
\hline \multicolumn{18}{|c|}{ Fatty acid composition } \\
\hline $12: 0^{*}$ & 0.25 & 0.019 & $0 \cdot 19$ & 0.017 & 0.17 & 0.013 & 0.20 & 0.012 & 0.19 & 0.008 & $0 \cdot 16$ & 0.004 & 0.027 & 0.039 & $<0.001$ & 0.004 & $0 \cdot 185$ \\
\hline $14: 0^{*}$ & 0.99 & 0.033 & 0.92 & 0.031 & 1.04 & 0.041 & 1.01 & 0.041 & 1.01 & 0.036 & 1.04 & 0.022 & 0.201 & 0.409 & 0.254 & 0.025 & 0.518 \\
\hline $15: 0 \dagger$ & 0.21 & 0.022 & 0.20 & 0.011 & 0.16 & 0.012 & 0.17 & 0.020 & 0.19 & 0.010 & 0.14 & 0.006 & 0.088 & 0.094 & 0.076 & 0.103 & 0.223 \\
\hline $16: 0^{*}$ & 21.6 & 0.38 & 20.6 & 0.28 & 21.6 & 0.32 & $21 \cdot 3$ & 0.28 & $21 \cdot 1$ & 0.29 & 21.5 & 0.22 & 0.952 & 0.051 & 0.858 & 0.011 & 0.372 \\
\hline $16: 1$ cis- $7^{*}$ & 0.32 & 0.011 & 0.29 & 0.011 & 0.26 & 0.012 & 0.34 & 0.015 & 0.28 & 0.004 & 0.30 & 0.012 & 0.060 & $<0.001$ & $<0.001$ & 0.566 & 0.068 \\
\hline $16: 1$ cis- $-9^{*}$ & $2 \cdot 36$ & 0.121 & 2.35 & 0.093 & 2.66 & 0.109 & 2.41 & 0.080 & 2.61 & 0.129 & $2 \cdot 67$ & 0.125 & 0.237 & 0.427 & 0.025 & 0.109 & 0.509 \\
\hline $17: 0^{*}$ & 0.40 & 0.046 & 0.39 & 0.026 & 0.35 & 0.033 & 0.43 & 0.048 & 0.44 & 0.028 & 0.33 & 0.025 & 0.573 & 0.932 & 0.097 & 0.010 & 0.471 \\
\hline $17: 1$ cis-9 & 0.26 & 0.025 & 0.21 & 0.017 & 0.21 & 0.025 & 0.21 & 0.016 & 0.21 & 0.016 & 0.22 & 0.015 & 0.418 & 0.161 & 0.316 & 0.758 & 0.397 \\
\hline 18:0† & 11.8 & 0.25 & $10 \cdot 6$ & 0.26 & $10 \cdot 7$ & 0.19 & 11.4 & 0.20 & $10 \cdot 7$ & 0.27 & 10.8 & 0.20 & 0.636 & 0.047 & 0.093 & 0.739 & 0.254 \\
\hline $18: 1^{\star}$ & 0.12 & 0.008 & 0.11 & 0.007 & 0.12 & 0.006 & 0.11 & 0.004 & 0.13 & 0.008 & 0.13 & 0.004 & 0.636 & 0.320 & 0.040 & 0.328 & 0.191 \\
\hline 18: 1 cis-9* & $32 \cdot 3$ & 1.35 & $33 \cdot 7$ & 0.81 & $36 \cdot 1$ & 1.15 & 33.9 & 0.71 & 34.2 & 0.88 & 37.1 & 0.53 & 0.190 & 0.389 & 0.002 & 0.004 & 0.848 \\
\hline $18: 1$ cis-11§ & 3.79 & 0.102 & 3.87 & 0.072 & 3.98 & 0.060 & 3.59 & 0.076 & 4.01 & 0.084 & 4.02 & 0.094 & 0.028 & 0.007 & 0.001 & 0.406 & 0.162 \\
\hline $18: 2 n-6^{\star}$ & $15 \cdot 7$ & 1.00 & $15 \cdot 0$ & 0.63 & $12 \cdot 7$ & 0.82 & $15 \cdot 5$ & 0.62 & 14.5 & 0.61 & 12.5 & 0.301 & 0.594 & 0.307 & $<0.001$ & $<0.001$ & 0.961 \\
\hline $18: 3 n-3$ & 0.41 & 0.022 & 0.35 & 0.015 & 0.29 & 0.023 & 0.44 & 0.023 & 0.34 & 0.018 & 0.30 & 0.006 & 0.780 & $<0.001$ & $<0.001$ & 0.006 & 0.977 \\
\hline $20: 0^{*}$ & 0.16 & 0.012 & 0.13 & 0.008 & 0.15 & 0.009 & 0.13 & 0.007 & 0.13 & 0.009 & 0.14 & 0.008 & 0.089 & 0.166 & 0.687 & 0.258 & 0.268 \\
\hline $20: 1$ cis- $11^{*}$ & 0.57 & 0.024 & 0.56 & 0.023 & 0.64 & 0.024 & 0.56 & 0.031 & 0.51 & 0.018 & 0.62 & 0.022 & 0.211 & 0.221 & 0.032 & $<0.001$ & 0.647 \\
\hline $20: 2 n-6^{*}$ & 0.42 & 0.016 & 0.44 & 0.022 & 0.37 & 0.027 & 0.44 & 0.030 & 0.38 & 0.019 & 0.39 & 0.013 & 0.671 & 0.410 & 0.048 & 0.147 & 0.085 \\
\hline $20: 3 n-3^{*}$ & 0.17 & 0.020 & 0.13 & 0.008 & 0.12 & 0.012 & 0.13 & 0.010 & 0.15 & 0.007 & 0.12 & 0.006 & 0.508 & 0.130 & 0.012 & 0.071 & 0.050 \\
\hline $20: 3 n-6^{*}$ & 0.41 & 0.035 & 0.43 & 0.025 & 0.36 & 0.034 & 0.38 & 0.029 & 0.41 & 0.026 & 0.33 & 0.018 & 0.280 & 0.526 & 0.117 & 0.008 & 0.975 \\
\hline $20: 4 n-6^{*}$ & 3.23 & 0.420 & 3.69 & 0.191 & 2.99 & 0.327 & 3.00 & 0.224 & 3.30 & 0.226 & $2 \cdot 68$ & 0.157 & 0.163 & 0.204 & 0.374 & 0.006 & 0.952 \\
\hline $20: 5 n-3^{*}$ & 0.10 & 0.021 & 0.11 & 0.009 & 0.07 & 0.009 & 0.09 & 0.012 & 0.08 & 0.006 & 0.06 & 0.006 & 0.092 & 0.708 & 0.056 & 0.006 & 0.373 \\
\hline $22: 4 n-6^{*}$ & 0.56 & 0.048 & 0.49 & 0.029 & 0.47 & 0.047 & 0.48 & 0.035 & 0.47 & 0.041 & 0.40 & 0.024 & 0.062 & 0.383 & 0.058 & 0.202 & 0.711 \\
\hline $22: 5 n-3^{*}$ & 0.40 & 0.065 & 0.36 & 0.018 & 0.31 & 0.032 & 0.31 & 0.023 & 0.32 & 0.033 & 0.25 & 0.029 & 0.035 & 0.789 & 0.087 & 0.031 & 0.776 \\
\hline $22: 6 n-3 \neq \S$ & 0.17 & 0.026 & 0.19 & 0.025 & 0.09 & 0.015 & 0.16 & 0.015 & ND & - & ND & - & 0.326 & - & - & - & - \\
\hline Others* & 3.77 & 0.439 & 4.60 & 0.300 & 3.94 & 0.375 & 3.78 & 0.291 & 4.35 & 0.277 & 3.80 & 0.172 & 0.621 & 0.053 & 0.801 & 0.038 & 0.916 \\
\hline \multicolumn{18}{|c|}{ Partial sums of fatty acids } \\
\hline$S F A^{*} \|$ & $35 \cdot 2$ & 0.467 & 33.1 & 0.581 & 34.1 & 0.457 & 34.3 & 0.436 & 33.5 & 0.464 & $34 \cdot 1$ & 0.312 & 0.636 & 0.006 & 0.130 & 0.087 & 0.338 \\
\hline MUFA*ף & 39.7 & 1.56 & $41 \cdot 1$ & 0.92 & $44 \cdot 0$ & 1.27 & $41 \cdot 2$ & 0.82 & 41.9 & 1.04 & $45 \cdot 0$ & 0.61 & 0.220 & 0.364 & 0.001 & 0.003 & 0.943 \\
\hline PUFA $^{*, * \star}$ & $21 \cdot 6$ & 1.52 & $21 \cdot 2$ & 0.87 & 17.8 & 1.27 & 20.9 & 0.89 & 20.0 & 0.92 & 17.1 & 0.49 & 0.311 & 0.597 & 0.002 & 0.001 & 0.964 \\
\hline$n-6$ PUFA ${ }^{*}+\dagger$ & 20.3 & 1.43 & 20.1 & 0.86 & $16 \cdot 9$ & 1.21 & 19.7 & 0.86 & $19 \cdot 1$ & 0.88 & $16 \cdot 3$ & 0.47 & 0.388 & 0.690 & 0.003 & 0.001 & 0.965 \\
\hline$n-3$ PUFA* $\ddagger \ddagger$ & 1.28 & 0.097 & $1 \cdot 12$ & 0.047 & 0.91 & 0.066 & $1 \cdot 13$ & 0.046 & 0.93 & 0.051 & 0.74 & 0.029 & 0.001 & 0.009 & $<0.001$ & $<0.001$ & 0.934 \\
\hline \multicolumn{18}{|l|}{ Fatty acid ratios } \\
\hline PUFA:SFA $\ddagger$ & 0.65 & 0.037 & & 0.057 & 0.52 & 0.048 & 0.59 & 0.033 & & 0.038 & 0.50 & 0.018 & 0.544 & 0.034 & 0.005 & 0.350 & 0.547 \\
\hline$n-6: n-3$ & $16 \cdot 4^{\mathrm{a}}$ & 0.43 & $18 \cdot 3^{\mathrm{b}, \mathrm{c}, \mathrm{a}}$ & 0.73 & $18 \cdot 4^{\mathrm{c}}$ & 0.40 & $17 \cdot 7^{\mathrm{c}, \mathrm{a}}$ & 0.57 & $20 \cdot 6^{\mathrm{d}, \mathrm{b}}$ & 0.57 & $22 \cdot 1^{\mathrm{d}}$ & 0.38 & $<0.001$ & $<0.001$ & $<0.001$ & 0.147 & 0.031 \\
\hline
\end{tabular}

NPD, normal protein diet; RPD, reduced protein diet; RPDL, reduced protein diet with leucine addition; ND, not determined.

a,b,c,d Mean values within a row with unlike superscript letters were significantly different $(P<0.05)$.

"Variable adjusted for IMF.

† Variable adjusted for the IMF $\times$ arginine $\times$ dietary protein level interaction.

$\mp$ Variable adjusted for the IMF $\times$ dietary protein level interaction

SVariable adjusted for the IMF $\times$ arginine interaction.

IISFA $=12: 0+14: 0+15: 0+16: 0+17: 0+18: 0+20: 0$.

18:1 cis-11+20:1 cis-11

PUFA $=18: 2 n-6+18: 3 n-3+20: 2 n-6+20: 3 n-3+20: 3 n-6+20: 4 n-6+20: 5 n-3+22: 4 n-6+22: 5 n-3+22: 6 n-3$.

I1 $n-6$ PUFA $=18: 2 n-6+20: 2 n-6+20: 3 n-6+20: 4 n-6+22: 4 n-6$. 
Table 4. Effect of dietary arginine (Arg), leucine and protein (Prot) levels on back fat thickness $\left(\mathrm{P}_{2}, \mathrm{~mm}\right)$, total fat (\% fat), fatty acid composition (\% total fatty acids), partial sums of fatty acids and related ratios in the subcutaneous adipose tissue of pigs

(Mean values with their standard errors)

\begin{tabular}{|c|c|c|c|c|c|c|c|c|c|c|c|c|c|c|c|c|c|}
\hline & \multicolumn{6}{|c|}{ Control } & \multicolumn{6}{|c|}{ Arginine } & \multicolumn{5}{|c|}{$P$} \\
\hline & \multicolumn{2}{|c|}{ NPD } & \multicolumn{2}{|c|}{ RPD } & \multicolumn{2}{|c|}{ RPDL } & \multicolumn{2}{|c|}{ NPD } & \multicolumn{2}{|c|}{ RPD } & \multicolumn{2}{|c|}{ RPDL } & \multicolumn{4}{|c|}{ Dietary protein level } & \multirow[b]{2}{*}{ Arg $\times$ Prot } \\
\hline & Mean & SE & Mean & SE & Mean & SE & Mean & SE & Mean & $\mathrm{SE}$ & Mean & SE & Arginine & $\begin{array}{l}\text { NPD } v \text {. } \\
\text { RPD }\end{array}$ & $\begin{array}{l}\text { NPD } v \text {. } \\
\text { RPDL }\end{array}$ & $\begin{array}{l}\text { RPD } v \text {. } \\
\text { RPDL }\end{array}$ & \\
\hline $\begin{array}{r}P_{2} \text { back fat } \\
\text { thickness }\end{array}$ & $17 \cdot 1$ & $1 \cdot 39$ & $18 \cdot 1$ & $1 \cdot 39$ & $19 \cdot 1$ & $1 \cdot 39$ & $15 \cdot 3$ & 1.39 & $20 \cdot 2$ & $1 \cdot 39$ & $20 \cdot 0$ & $1 \cdot 39$ & 0.720 & 0.041 & 0.021 & $0 \cdot 780$ & 0.349 \\
\hline Total fat & $61 \cdot 4$ & $2 \cdot 02$ & $64 \cdot 2$ & $2 \cdot 02$ & $65 \cdot 3$ & $2 \cdot 02$ & $61 \cdot 7$ & $2 \cdot 02$ & $70 \cdot 6$ & $2 \cdot 02$ & $70 \cdot 6$ & $2 \cdot 02$ & 0.020 & 0.005 & 0.003 & 0.804 & 0.280 \\
\hline \multicolumn{18}{|l|}{$\begin{array}{l}\text { Fatty acid } \\
\text { composition }\end{array}$} \\
\hline $12: 0$ & 0.06 & 0.003 & 0.05 & 0.002 & 0.06 & 0.003 & 0.06 & 0.002 & 0.06 & 0.004 & 0.05 & 0.003 & 0.988 & 0.605 & 0.691 & 0.901 & 0.060 \\
\hline $14: 0^{*}$ & 1.09 & 0.025 & 1.07 & 0.018 & 1.06 & 0.022 & 1.06 & 0.028 & $1 \cdot 13$ & 0.037 & 1.04 & 0.027 & 0.867 & 0.348 & 0.448 & 0.075 & 0.297 \\
\hline $15: 0$ & 0.06 & 0.005 & 0.05 & 0.004 & 0.06 & 0.007 & 0.07 & 0.009 & 0.05 & 0.006 & 0.05 & 0.006 & 0.707 & 0.037 & 0.077 & $0 \cdot 830$ & 0.663 \\
\hline $16: 0^{*}$ & 21.6 & 0.30 & $21 \cdot 2$ & 0.29 & 21.3 & 0.32 & $21 \cdot 1$ & 0.35 & $22 \cdot 1$ & 0.38 & $21 \cdot 2$ & 0.24 & 0.780 & 0.367 & 0.737 & 0.173 & 0.090 \\
\hline $16: 1$ cis $-7^{*}$ & 0.39 & 0.022 & 0.38 & 0.022 & 0.37 & 0.019 & 0.44 & 0.033 & 0.35 & 0.013 & 0.36 & 0.019 & 0.901 & 0.054 & 0.073 & 0.898 & 0.165 \\
\hline $16: 1$ cis-9 & 1.88 & 0.105 & 1.76 & 0.105 & 1.81 & 0.119 & 1.68 & 0.075 & 1.79 & 0.102 & 1.66 & 0.078 & 0.197 & 0.959 & 0.638 & 0.693 & 0.480 \\
\hline $17: 0$ & 0.52 & 0.039 & 0.44 & 0.032 & 0.47 & 0.046 & 0.53 & 0.060 & 0.45 & 0.030 & 0.45 & 0.028 & 0.985 & 0.064 & 0.131 & 0.766 & 0.841 \\
\hline $17: 1$ cis-9 & 0.43 & 0.028 & 0.35 & 0.030 & 0.38 & 0.035 & 0.40 & 0.040 & 0.37 & 0.033 & 0.35 & 0.024 & 0.629 & 0.090 & 0.144 & 0.774 & 0.658 \\
\hline $18: 0$ & 11.5 & 0.33 & 11.3 & 0.54 & 11.3 & 0.53 & 11.4 & 0.48 & $12 \cdot 4$ & 0.46 & 11.8 & 0.34 & 0.120 & 0.478 & 0.822 & 0.629 & 0.392 \\
\hline $18: 1$ & 0.09 & 0.006 & 0.09 & 0.010 & 0.08 & 0.005 & 0.08 & 0.003 & 0.09 & 0.005 & 0.08 & 0.005 & 0.311 & 0.502 & 0.587 & 0.297 & 0.577 \\
\hline $18: 1$ cis-9 & 38.0 & 0.39 & $39 \cdot 2$ & 0.62 & $39 \cdot 1$ & 0.54 & $37 \cdot 1$ & 0.35 & $39 \cdot 0$ & 0.48 & 39.9 & 0.64 & 0.769 & 0.002 & $<0.001$ & 0.521 & 0.239 \\
\hline $18: 1 c i s-11$ & $2 \cdot 60$ & 0.055 & 2.54 & 0.111 & 2.53 & 0.115 & 2.45 & 0.070 & 2.47 & 0.078 & 2.48 & 0.064 & 0.199 & 0.757 & 0.784 & 0.972 & 0.781 \\
\hline $18: 2 n-6^{*}$ & $17 \cdot 7^{a, b}$ & 0.42 & $17 \cdot 7^{\mathrm{a}, \mathrm{b}}$ & 0.62 & $17 \cdot 5^{\mathrm{a}, \mathrm{b}}$ & 0.33 & $19 \cdot 5^{\mathrm{b}}$ & 0.76 & $16 \cdot 5^{\mathrm{a}}$ & 0.33 & $16 \cdot 9^{a, b}$ & 0.79 & 0.956 & 0.010 & 0.030 & 0.815 & 0.030 \\
\hline $18: 3 n-3$ & 1.05 & 0.045 & 0.94 & 0.040 & 0.95 & 0.020 & $1 \cdot 11$ & 0.054 & 0.88 & 0.026 & 0.85 & 0.049 & 0.300 & $<0.001$ & $<0.001$ & 0.882 & 0.226 \\
\hline $20: 0$ & 0.23 & 0.009 & 0.21 & 0.012 & 0.20 & 0.007 & 0.20 & 0.009 & $0 \cdot 19$ & 0.008 & 0.20 & 0.009 & 0.058 & 0.245 & 0.358 & 0.707 & 0.247 \\
\hline $20: 1$ cis-11 & 0.76 & 0.036 & 0.81 & 0.055 & 0.82 & 0.025 & 0.73 & 0.050 & 0.72 & 0.035 & 0.84 & 0.039 & 0.309 & 0.653 & 0.036 & 0.123 & 0.415 \\
\hline $20: 2 n-6^{*}$ & $0.79^{a, b}$ & 0.023 & $0.87^{a, b}$ & 0.038 & $0.83^{a, b}$ & 0.020 & $0.83^{a, b}$ & 0.040 & $0.73^{\mathrm{a}}$ & 0.031 & $0.84^{\mathrm{b}}$ & 0.028 & 0.302 & 0.688 & 0.421 & 0.189 & 0.011 \\
\hline $20: 3 n-3$ & 0.11 & 0.005 & 0.11 & 0.006 & 0.12 & 0.007 & 0.12 & 0.011 & 0.09 & 0.006 & $0 \cdot 10$ & 0.007 & 0.237 & 0.025 & 0.385 & 0.109 & 0.143 \\
\hline $20: 3 n-6$ & 0.31 & 0.015 & 0.28 & 0.015 & 0.30 & 0.013 & 0.35 & 0.033 & 0.27 & 0.007 & 0.28 & 0.020 & 0.813 & 0.006 & 0.058 & 0.305 & 0.406 \\
\hline $20: 4 n-6$ & 0.15 & 0.007 & 0.13 & 0.015 & 0.13 & 0.010 & $0 \cdot 16$ & 0.015 & 0.13 & 0.007 & 0.15 & 0.013 & 0.285 & 0.054 & 0.191 & 0.508 & 0.924 \\
\hline Others & $0.46^{a, b}$ & 0.052 & $0.49^{a, b}$ & 0.037 & $0.71^{b}$ & 0.081 & $0.48^{a, b}$ & 0.054 & $0.42^{\mathrm{a}, \mathrm{b}}$ & 0.059 & $0.42^{\mathrm{a}}$ & 0.048 & 0.017 & 0.731 & 0.136 & 0.069 & 0.046 \\
\hline \multicolumn{18}{|l|}{$\begin{array}{l}\text { Partial sums of } \\
\text { fatty acids }\end{array}$} \\
\hline SFA $†$ & 34.8 & 0.61 & 34.2 & 0.79 & $34 \cdot 3$ & 0.80 & $34 \cdot 2$ & 0.79 & $36 \cdot 7$ & 0.70 & $35 \cdot 3$ & 0.51 & 0.119 & 0.194 & 0.658 & 0.363 & 0.110 \\
\hline MUFA & 44.2 & 0.49 & $45 \cdot 2$ & 0.77 & $45 \cdot 1$ & 0.77 & $42 \cdot 9$ & 0.41 & $44 \cdot 7$ & 0.61 & $45 \cdot 6$ & 0.66 & 0.461 & 0.021 & 0.004 & 0.578 & 0.318 \\
\hline PUFA $^{*} \S$ & $20 \cdot 1^{\mathrm{a}, \mathrm{b}}$ & 0.47 & $20 \cdot 0^{\mathrm{a}, \mathrm{b}}$ & 0.65 & $19 \cdot 8^{\mathrm{a}, \mathrm{b}}$ & 0.36 & $22 \cdot 1^{\mathrm{b}}$ & 0.87 & $18 \cdot 6^{\mathrm{a}}$ & 0.36 & $19 \cdot 1^{\mathrm{a}, \mathrm{b}}$ & 0.86 & 0.885 & 0.006 & 0.025 & 0.740 & 0.029 \\
\hline$n-6$ PUFA $\|$ & $19 \cdot 0^{\mathrm{a}, \mathrm{b}}$ & 0.43 & $18 \cdot 9^{\mathrm{a}, \mathrm{b}}$ & 0.61 & $18 \cdot 8^{\mathrm{a}, \mathrm{b}}$ & 0.34 & $20 \cdot 8^{\mathrm{b}}$ & 0.82 & $17 \cdot 6^{\mathrm{a}}$ & 0.35 & $18 \cdot 1^{\mathrm{a}, \mathrm{b}}$ & 0.81 & 0.937 & 0.009 & 0.033 & 0.732 & 0.025 \\
\hline$n$-3 PUFA" & $1 \cdot 16$ & 0.046 & 1.05 & 0.043 & 1.07 & 0.023 & 1.23 & 0.062 & 0.97 & 0.027 & 0.96 & 0.053 & 0.271 & $<0.001$ & $<0.001$ & 0.885 & 0.170 \\
\hline \multicolumn{18}{|l|}{$\begin{array}{l}\text { Fatty acid } \\
\text { ratios }\end{array}$} \\
\hline PUFA:SFA* & 0.58 & 0.022 & 0.59 & 0.026 & 0.58 & 0.022 & 0.65 & 0.041 & 0.51 & 0.020 & 0.55 & 0.031 & 0.682 & 0.040 & 0.136 & 0.545 & 0.050 \\
\hline$n-6: n-3$ & $16 \cdot 8$ & 0.48 & $18 \cdot 3$ & 0.43 & $17 \cdot 6$ & 0.21 & $17 \cdot 3$ & 0.54 & $17 \cdot 8$ & 0.45 & $18 \cdot 7$ & 0.54 & 0.290 & 0.043 & 0.024 & 0.838 & 0.188 \\
\hline
\end{tabular}

NPD, normal protein diet; RPD, reduced protein diet; RPDL, reduced protein diet with leucine addition.

a,b Mean values within a row with unlike superscript letters were significantly different $(P<0.05)$.

* Variables adjusted for total fat.

TSFA $=12: 0+14: 0+15: 0+16: 0+17: 0+18: 0+20: 0$.

¥MUFA $=16: 1$ cis- $7+16: 1$ cis- $9+17: 1$ cis- $9+18: 1+18: 1$ cis- $9+18: 1$ cis- $11+20: 1$ cis- 11

$\S$ PUFA $=18: 2 n-6+18: 3 n-3+20: 2 n-6+20: 3 n-3+20: 3 n-6+20: 4 n-6$

II $n-6$ PUFA $=18: 2 n-6+20: 2 n-6+20: 3 n-6+20: 4 n-6$.

I $n-3$ PUFA $=18: 3 n-3+20: 3 n-3$. 
fed a diet without amino acid supplementation. The RPD $(P=0.005)$ and RPDL $(P=0.003)$ also had a $10 \%$ increase in total fat content when compared with the NPD.

The most representative fatty acids in SAT were 18:1cis-9 $(37-40 \%$ of total FAME), 16:0 (21-22\%), 18:2n-6 (16-19\%), 18:0 (11-12\%) and 18:1cis-11 (2-3\%) for all the experimental groups. Of the individual fatty acids, three were affected by the arginine $\times$ protein level interaction, including the predominant fatty acids $18: 2 n-6,20: 2 n-6$ and the 'others' detected fatty acids. Neither arginine nor leucine changed the fatty acid profile in SAT. The reduction in the level of dietary protein resulted in an increase of the percentages of $18: 1$ cis9 (RPD and RPDL) and 20:1cis-11 (RPDL) when compared with the NPD. Regarding the partial sums of fatty acids (Table 4), a significant interaction between arginine and dietary protein level was observed for PUFA $(P=0.029)$ and $n-6$ PUFA $(P=0 \cdot 025)$, while a significant effect on NPD $v$ RPD $(P=0 \cdot 021)$ and NPD $v$. RPDL ( $P=0 \cdot 004)$ was found for MUFA, with higher values in pigs fed the RPD and RPDL. In terms of fatty acid ratios, the RPD decreased the PUFA:SFA ratio $(P=0 \cdot 040)$ when compared with the NPD. However, the pigs fed the RPD $(P=0.043)$ and RPDL $(P=0.024)$ had higher $n-6: n-3$ ratios when compared with those fed the NPD.

\section{Gene expression levels in muscle and subcutaneous adipose tissue}

The results presented above showed different responses of the longissimus lumborum muscle and SAT to dietary manipulations in crossbred pigs. The expression analysis of key genes associated with lipid metabolism was carried out in order to elucidate whether the tissue-specific effects of dietary arginine, leucine and protein level are associated with modulation of the gene expression. Figs. 1 and 2 show the expression levels of
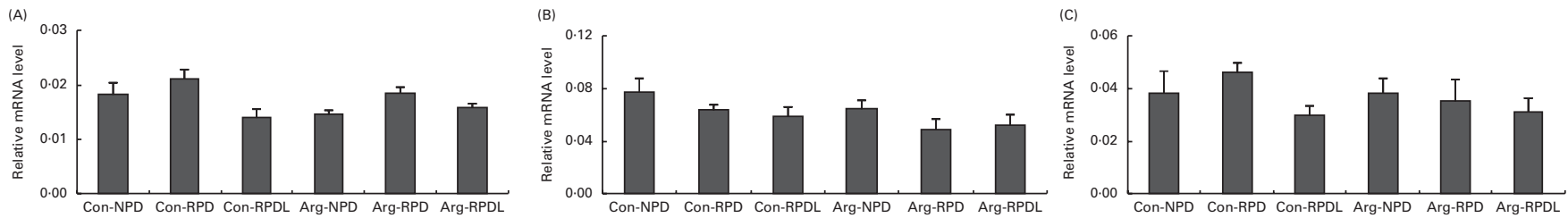
(D)

(E)
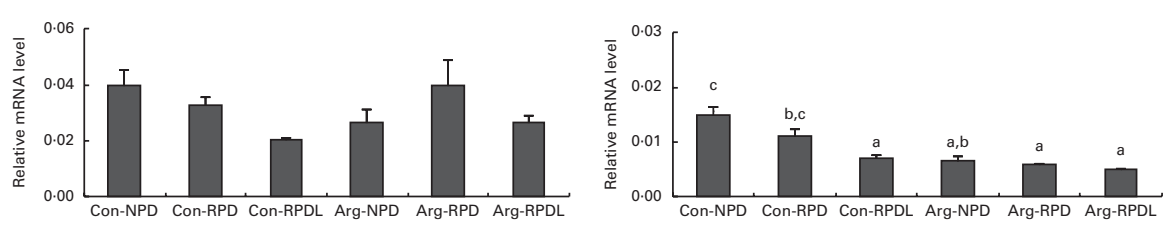

(F)
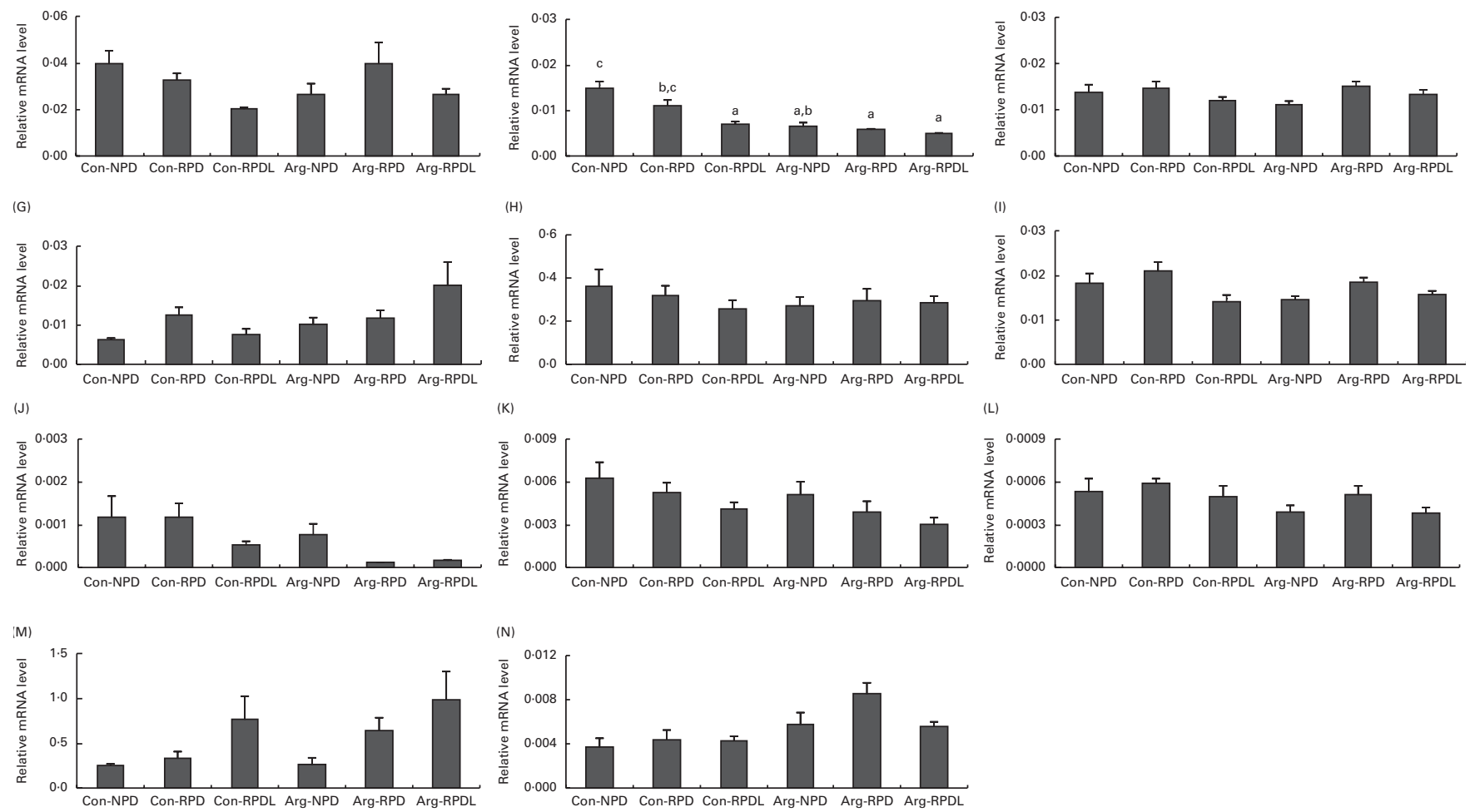

Fig. 1. Effect of dietary arginine, leucine and protein levels on gene expression in the longissimus lumborum muscle of pigs: (A) acetyl-CoA carboxylase (ACACA), (B) carnitine $O$-acetyltransferase (CRAT), (C) carnitine palmitoyltransferase 1 (CPT-1B), (D) fatty acid binding protein 4 (FABP4) (arginine, $P=0.026$; normal protein diet (NPD) $v$. reduced protein diet with leucine addition (RPDL), $P=0.026$; reduced protein diet (RPD) $v$. RPDL, $P=0.017$ ), (E) fatty acid desaturase 1 (FADS1) (arginine $\times$ protein level, $P=0.008$ ), (F) fatty acid desaturase 2 (FADS2), (G) fatty acid synthase (FASN) (arginine, $P=0.030 ;$ NPD $v$. RPDL, $P=0.031$ ), (H) GLUT4, (I) lipoprotein lipase (LPL) (NPD v. RPD, $P=0.043$; RPD v. RPDL, $P=0.001)$, (J) MLX-interacting protein-like ( $M L X I P L)$ (arginine, $P=0.001 ; \mathrm{NPD} v$. RPDL, $P=0.004$ ), (K) PPAR $($ NPD v. RPDL, $P=0.016$ ), (L) PPAR $($ arginine, $P=0.041$ ), (M) stearoyl-CoA desaturase (SCD) (NPD v. RPD, $P=0.024 ;$ NPD v. RPDL, $P=0.006$ ) and $(\mathrm{N})$ sterol regulatory element-binding protein 1 (SREBP1) (arginine, $P=0.001$ ). Con, control diet; Arg, arginine. Values are means, with their standard errors represented by vertical bars. ${ }^{\text {a,b,c }}$ Mean values with unlike letters were significantly different $(P<0.05)$. 'Arginine' and arginine $\times$ protein level mean the significant effect of arginine or the interaction between arginine and protein level, respectively. For FABP4, variable adjusted for the intramuscular fat (IMF) $\times$ arginine interaction. For MLXIPL, variable adjusted for IMF. 
fourteen genes controlling lipid metabolism analysed in the longissimus lumborum muscle and SAT of pigs, respectively.

In longissimus lumborum muscle, the expression level of nine of the fourteen genes was affected, at least, by one dietary treatment. A significant interaction $(P=0 \cdot 008)$ between arginine and protein level was found for the expression level of the FADS1 gene. Arginine increased the mRNA levels of FABP4 $(P=0.026), F A S N(P=0.030)$ and SREBP1 $(P=0 \cdot 001)$, and decreased the expression levels of $M L X I P L$ $(P=0.001)$ and PPARG $(P=0.041)$. The RPDL decreased the expression levels of MLXIPL $(P=0.004)$ and PPARA $(P=0.016)$, and increased FASN mRNA $(P=0.031)$, when compared with the NPD. The relative expression level of the $L P L$ gene was higher $(P=0.043)$ in pigs fed the RPD relative to the NPD. Finally, the RPD $(P=0.024)$ and RPDL $(P=0.006)$ increased the relative expression levels of the $S C D$ gene when compared with the NPD.
In SAT, the mRNA levels of eleven of the fourteen genes analysed were affected by, at least, one dietary treatment. A significant interaction between arginine and dietary protein level was found for FABP4 $(P=0.026)$, PPARG $(P=0.009)$ and SREBP1 $(P=0.044)$. Arginine increased the mRNA expression of FASN $(P=0.022)$ and $S C D(P=0 \cdot 016)$. The RPD increased the expression levels of FASN $(P=0.049)$ and $L P L$ $(P=0.004)$ when compared with the NPD. The RPDL increased the mRNA levels of FADS1 $(P<0.05)$, FADS2 $(P<0.05)$ and $S C D(P<0.01)$ when compared with the NPD and RPD. The expression levels of CEBPA $(P=0.002)$ and CRAT ( $P=0.043)$ were down-regulated, and that of $A C A C A$ ( $P=0.011)$ up-regulated, in pigs fed the RPDL, when compared with those fed the NPD. Finally, the RPDL increased the mRNA levels of $S C D$ when compared with the NPD $(P<0 \cdot 001)$ and RPD $(P=0 \cdot 008)$.
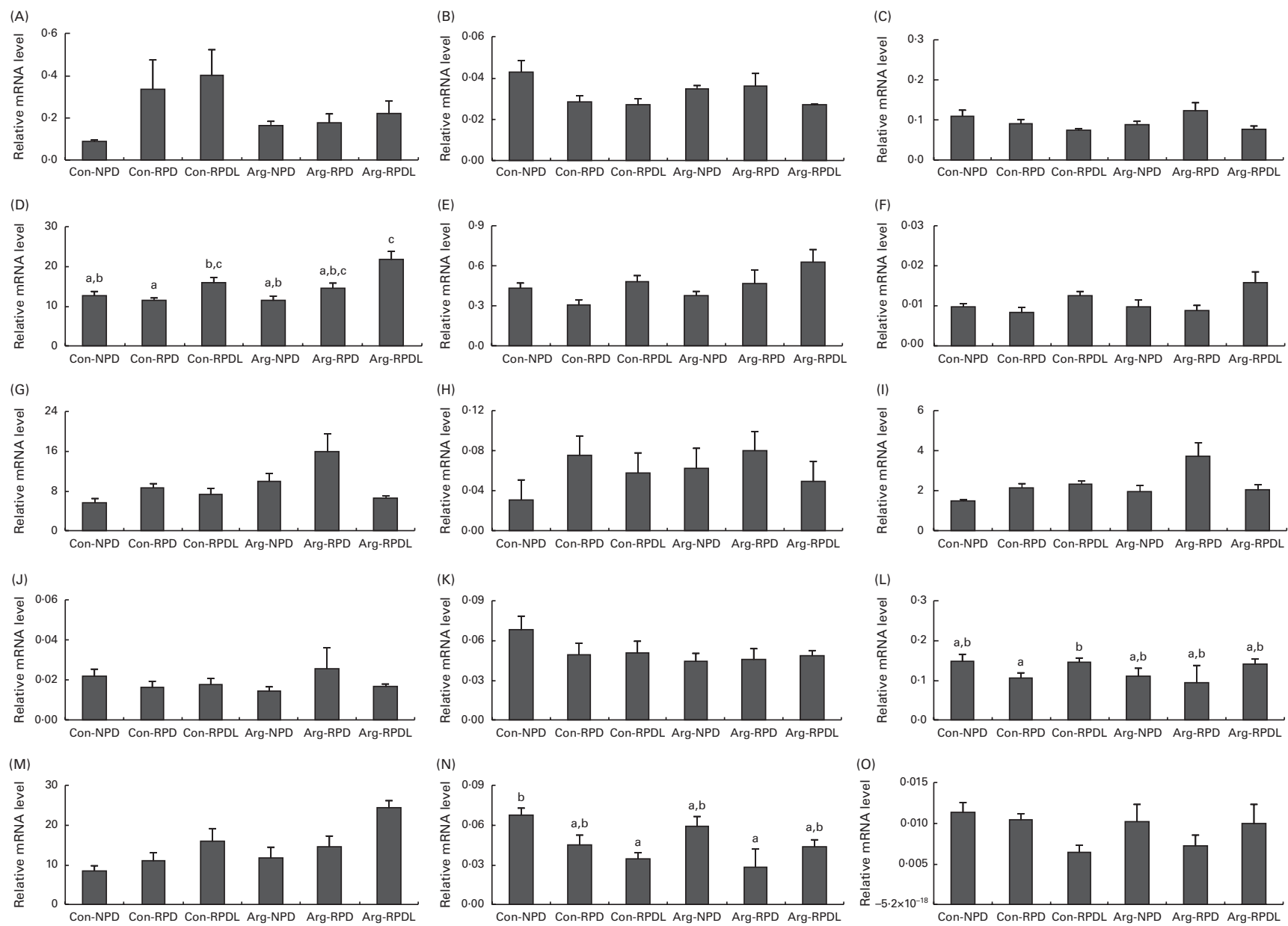

Fig. 2. Effect of dietary arginine, leucine and protein levels on gene expression in the subcutaneous adipose tissue (SAT) of pigs: (A) acetyl-CoA carboxylase $(A C A C A)$ (normal protein diet (NPD) $v$. reduced protein diet with leucine addition (RPDL), $P=0.011$ ), (B) CCAAT/enhancer binding protein $\alpha$ (CEBPA) (NPD $v$. RPDL, $P=0.002$ ), (C) carnitine $O$-acetyltransferase (CRAT) (NPD $v$. RPDL, $P=0.043$; reduced protein diet (RPD) $v$. RPDL, $P=0.034$ ), (D) fatty acid binding protein 4 (FABP4) (arginine $\times$ protein level, $P=0.026$ ), (E) fatty acid desaturase 1 (FADS1) (NPD $v$. RPDL, $P=0.021 ; R P D v$. RPDL, $P=0.041$ ), (F) fatty acid desaturase 2 (FADS2) (NPD v. RPDL, $P=0.023$; RPD $v$. RPDL, $P=0.004$ ), (G) fatty acid synthase (FASN) (arginine, $P=0.022 ; \mathrm{NPD} v . \mathrm{RPD}, P=0.049 ; \mathrm{RPD} v$. RPDL, $P=0.014)$, (H) glucose transporter type 4, (I) lipoprotein lipase (LPL) (NPD v. RPD, $P=0.004)$, (J) MLX-interacting protein-like (MLXIPL), (K) $P P A R \alpha(P P A R A)$, (L) PPAR $\gamma(P P A R G)$ (arginine $\times$ protein level, $P=0.009$ ), (M) stearoyl-CoA desaturase (SCD) (arginine, $P=0.016$; NPD v. RPDL, $P<0.001$; RPD v. RPDL, $P=0.008$ ), $(\mathrm{N})$ sterol regulatory element-binding protein 1 (SREBP1) (arginine $\times$ protein level, $P=0.044$ ) and (O) LPL muscle/SAT. Con, control diet; Arg, arginine. Values are means, with their standard errors represented by vertical bars. ${ }^{a, b, c}$ Mean values with unlike letters were significantly different $(P<0 \cdot 05)$. 'Arginine' and arginine $\times$ protein level mean the significant effect of arginine or the interaction between arginine and protein level, respectively. For PPARG and SREBP1, variable adjusted for the total fat $x$ arginine $\times$ reduced protein interaction. 
Correlation between fatty acid composition and gene expression levels

Table 5 presents the correlation coefficients $(r)$ for fatty acid composition and gene expression levels, adjusted with IMF as the covariate for longissimus lumborum muscle, and fatty acid composition with total fat as the covariate for SAT. There were a much larger number of significant correlations between fatty acid composition and gene expression in the SAT relative to the muscle.

In longissimus lumborum muscle, only the 18:0 fatty acid $(P<0.05)$ was positively and moderately correlated $(0.7 \geq r \geq 0.3)$ with $F A D S 1$. Strong positive correlations $(P<0.001)$ were observed between FASN and $A C A C A$, and between FASN and $S C D$. Expressions of PPARA $(P<0 \cdot 001)$ and $M L X I P L \quad(P<0.001)$ were positively correlated with $C P T-1 B, C R A T$ and FADS1. Furthermore, positive correlations were found between the expressions of PPARA and GLUT4 $(P<0.001), P R A R A$ and MLXIPL $(P<0.01), P P A R G$ and $L P L$ $(P<0.001)$, and $L P L$ and FADS1 $(P<0.001)$. GLUT4 was positively correlated with $C R A T(P<0 \cdot 001)$, while FADS1 was positively correlated with $C R A T(P<0 \cdot 001)$. Finally, the mRNA level of CRAT was positively and highly correlated $(r>0.7)$ with that of $C P T-1 B(P<0.001)$.

In SAT, 16:0 $(P<0 \cdot 01), 18: 0(P<0 \cdot 01)$ and SFA $(P<0 \cdot 01)$ were positively and moderately correlated with the expression of CRAT and $L P L$ genes. Furthermore, 18:0 and SFA were also positively correlated with $F A S N(P<0 \cdot 01)$. A moderate positive correlation was found between the gene expression of 18:0 and SCD $(P<0.05)$. MUFA $(P<0.01)$ and $18: 1$ cis-9 $(P<0.01)$ were negatively and moderately correlated with $C E B P A$, and 18:1cis-9 was positively correlated with $S C D(P<0 \cdot 01)$. PUFA and 18:2n-6 were negatively correlated with FABP4 $(P<0.05), \quad F A D S 2 \quad(P<0.05), \quad L P L \quad(P<0.05)$ and $S C D$ $(P<0 \cdot 01)$. Significantly positive correlations in the SAT were observed between the mRNA levels of $S C D$ and $A C A C A$ $(P<0.01), \quad F A B P 4 \quad(P<0.01), \quad F A D S 1 \quad(P<0.001), \quad F A D S 2$ $(P<0.001), F A S N(P<0.01)$ and GLUT4 $(P<0.001)$. It was also found that the expression of $P P A R A$ was positively correlated with those of $C R A T(P<0.05), F A D S 1(P<0.05)$, FADS 2 $(P<0.05)$ and MLXIPL $(P<0.001)$, while MLXIPL was positively correlated with CEBPA $(P<0.05), C R A T(P<0.001)$, FADS1 $(P<0.001)$, FADS2 $(P<0.05)$, FASN $(P<0.001)$, GLUT4 $(P<0.001)$ and $L P L(P<0.001) . L P L$ and FASN were positively correlated with $C R A T(P<0.001)$ and $F A D S 1$ $(P<0.05)$, and $L P L$ was also positively correlated with $F A S N$ $(P<0.001)$ and GLUT4 $(P<0.001)$. In addition, GLUT4 was positively correlated with ACACA $(P<0.001), \quad F A D S 1$ $(P<0.05)$, FADS2 $(P<0.05)$ and FASN $(P<0.001)$. Finally, $F A D S 2$ was positively correlated with FABP4 $(P<0 \cdot 01)$ and FADS1 $(P<0 \cdot 001)$.

\section{Discussion}

In the present study, a 19\% RPD (16 v. 13\% of crude protein) fed during the growing-finishing phase of the commercial crossbred (lean) pigs resulted in a $45-48 \%$ increase in IMF. This is consistent with the findings of previous studies, which indicated that a range of dietary protein concentrations (e.g. 21 v. $18 \%^{(11)}$ and 17 v. $15 \%^{(36)}$ ) increased the IMF content in commercial crossbred pigs. It has also recently been shown by our group that dietary lysine restriction $(0 \cdot 7$ $v$. $0.4 \%$ of L-lysine) is needed to increase IMF in commercial crossbred pigs, and that the IMF increase is mediated via the up-regulation of the gene expression of $S C D^{(12)}$, which encodes for the key lipogenic enzyme of MUFA biosynthesis. The results of the present study confirm the up-regulation of the gene expression of $S C D$ by the RPD in pig muscle.

Our initial hypothesis was that tissue-specific responses to the RPD in terms of fat content and fatty acid composition in crossbred pigs could be increased by the dietary supplementation of arginine and leucine. This hypothesis was based on data of the literature, which suggested that dietary supplementation of either arginine $e^{(8,37)}$ or leucine ${ }^{(9,10,38)}$ can result in increased IMF content. We hypothesised that if these feeding strategies increase IMF through different mechanisms, they might have additive effects on IMF levels if used together. We also proposed that fat-partitioning effects of arginine- and leucine-supplemented diets are mediated via the tissue-specific regulation of the expression of genes controlling lipid metabolism in muscle and SAT. The present study investigated the above-mentioned aspects, and the results suggested that neither arginine nor leucine results in an additional increase of IMF in longissimus lumborum muscle.

The results of the present study on the effects of arginine supplementation are in line with those of Go et al. $^{(39)}$, who found that dietary arginine supplementation does not increase IMF in pigs. However, Tan et al. ${ }^{(8)}$ and Ma et al. ${ }^{(37)}$ reported an increase in IMF content in experiments that used $1 \%$ of dietary arginine supplementation. This discrepancy might be explained by the use of pigs with distinct genetic background, mainly different predisposition for fat deposition. In fact, our previous results ${ }^{(12)}$ showed that the increase in IMF under the RPD depends on the genetic background of pigs. In particular, the IMF increase under the RPD was observed in genetically lean but not fatty pig breeds. Furthermore, Tan et al. ${ }^{(8)}$, who used Duroc $\times$ Large White $\times$ Landrace crossbred pigs fed a diet with protein and arginine levels similar to those reported in the present study, observed higher IMF contents when compared with the animals from the control group of the present study (1.81 v. 1.34\%). In addition, Ma et $a l^{(37)}$ fed finishing crossbred pigs (Du $\times($ Chang $\times$ Da) ) with dietary protein and arginine levels similar to those described in the present experiment, and obtained IMF contents similar to those observed in the control animals of the present study $(1.31 v .1 \cdot 34 \%)$ but, in contrast to our data, showed a significant IMF increase with arginine supplementation.

Regarding the dietary leucine supplementation of RPD, the present results are in disagreement with those of Hyun et al. ${ }^{(9)}$, who described increased IMF with leucine supplementation of diets restricted in lysine. Since the levels of crude protein and lysine were similar in both studies, the difference between the results of the present study and the data of Hyun et al. ${ }^{(9)}$ might be explained by the use of a different genetic background (PIC line $327 \times \mathrm{C} 22$ ). It is also important to point out that Hyun et al. ${ }^{(9)}$ studied the effect of dietary 


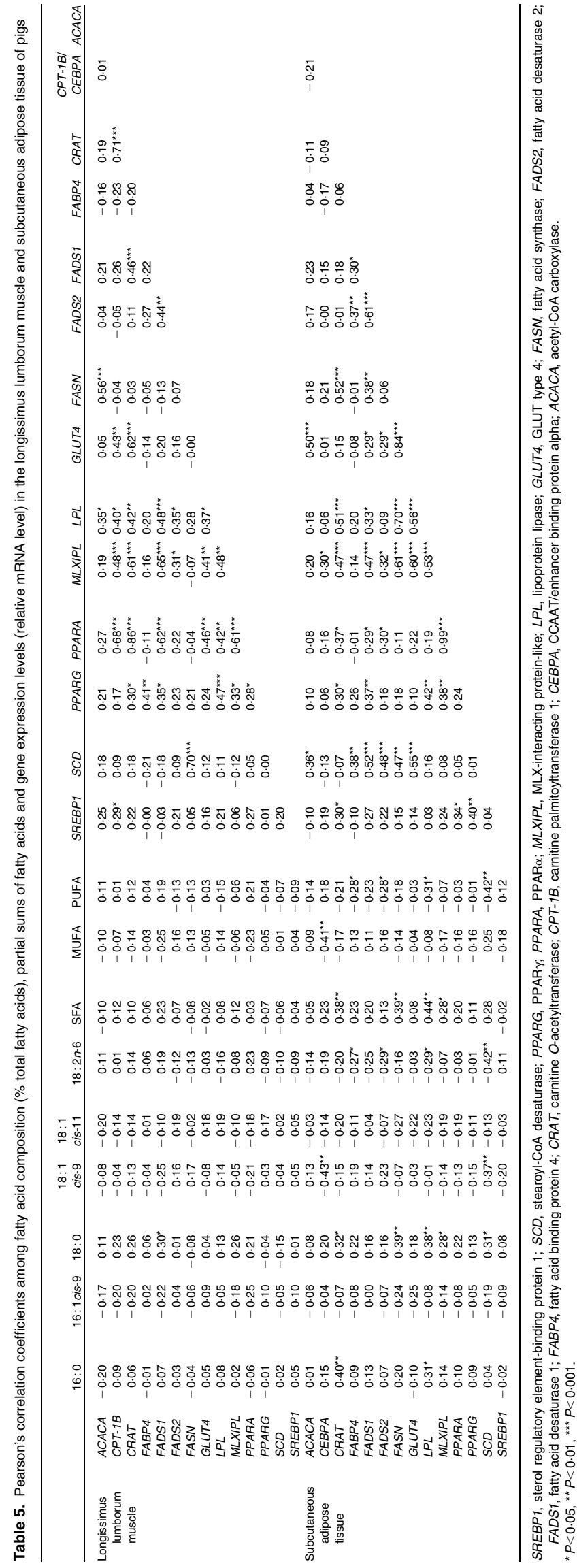

leucine supplementation on a NPD and not on a RPD, as used in our experiment. In sum, the present results do not indicate any additional effect of dietary arginine and/or leucine supplementation on increased IMF promoted by the RPD alone.

In terms of dietary effects on fatty acid composition, the animals fed the diet supplemented with arginine had a lower percentage of long-chain $n$-3 PUFA, which was mainly due to a decrease in docosapentaenoic acid level. The docosapentaenoic acid decrease was accompanied by the lower expression of FADS1 and MLXIPL genes and the higher expression of the SREBP1 gene. $\triangle 5$-Desaturase is an enzyme directly involved in the biosynthesis of long-chain PUFA $^{(40)}$. It is possible that changes in $\Delta 5$-desaturase gene expression (FADS1 gene) and activity are linked to the changes in the level of the transcription factors SREBP 1 and $M L X I P L$ observed in the present study. In fact, the present observation of the lower concentration of PUFA in muscle membranes and the up-regulation of SREBP1 under the arginine-supplemented diet are consistent with the central role of SREBP1 in the allostatic regulation of membrane lipid composition proposed by Hagen et al. ${ }^{(41)}$. MLXIPL also participates in the regulation of the expression of lipogenic enzymes, and it has been described to act synergistically with SREBP ${ }^{(42)}$.

In contrast to the FADS1 gene, the present study did not find any significant effects of arginine on the gene expression of SCD. This is not in agreement with the findings of Tan et $a l .{ }^{(7)}$, who reported that arginine supplementation increased 18:1cis-9 and decreased 18:0 and 18:2n-6, which was explained by the arginine-dependent activation of SCD, a key enzyme in the formation of oleic acid. These differences might be explained by the variations in experimental conditions, mainly by the different genetic line of pigs used (Duroc $\times$ Large White $\times$ Landrace), which determines distinct IMF levels for control animals.

The present study indicated that the supplementation of RPD with leucine changed the fatty acid profile in pig muscle. The up-regulation of $S C D(P=0.09)$ and FASN in muscle was consistently reflected by higher proportions of 18:1 cis-9 and 16:0 fatty acids. Moreover, most of the muscle PUFA decreased under dietary leucine supplementation. As the supplementation of RPD with leucine did not increase IMF $(P=0.801)$, it is reasonable to assume that the proportion of membrane phospholipids and TAG in muscle remains fairly constant. Thus, the increase in 18:1cis-9 and $16: 0$ should result in a direct replacement of the majority of PUFA in muscle lipids. Furthermore, the expression of the transcription factors $M L X I P L$ and PPARA, as well as the expression of $F A B P 4$, were down-regulated by leucine supplementation, which is not easy to relate with the apparent replacement of PUFA by 16:0 and 18:1cis-9. In addition, the expression of PPARA in muscle was observed to be up-regulated in pigs fed the NPD when compared with those fed the RPDL, thus suggesting enhanced lipid oxidation.

In the present study, the RPD increased total fat in SAT and back fat thickness in pigs. Michal et al. ${ }^{(43)}$ reported that the FABP 4 protein is responsible for the transport of fatty acids 
in adipocytes, and its content is associated with back fat thickness. However, in the present study, the mRNA levels of FABP4 did not increase in pigs fed the RPD. Also, this diet increased 18:1cis-9 and MUFA content, which may be explained by a higher expression of the gene controlling lipogenesis (FASN) and expression of $L P L$.

The present study established that dietary arginine supplementation increased total fat content in SAT, without any effect on fatty acid composition and back fat thickness at the $\mathrm{P}_{2}$ site. The increased fat content of SAT is consistent with the up-regulation of the expression of FASN and $S C D$ genes in animals fed an arginine-supplemented diet. However, these data do not support the results of previous works, in which arginine was suggested to increase lipolysis and inhibit lipogenesis in the adipose tissue of pigs $^{(8)}$, rats $^{(44)}$ and broilers ${ }^{(45)}$. This discrepancy of the results in pigs might be explained by the genetic line used by Tan et al. ${ }^{(8)}$, which was different from the genetic background used in the present study (Duroc $\times$ Large White $\times$ Landrace $v$. Duroc $\times$ Large White $\times$ Landrace $\times$ Pietrain). However, the crude protein and lysine levels used are similar in the two experiments. Also, Tan et al. ${ }^{(7)}$ reported a decrease of $18: 1$ cis-9 in SAT with arginine supplementation, which was not confirmed by the present results.

In SAT, leucine supplementation of RPD did not affect total fat content, fatty acid composition and back fat thickness at the $\mathrm{P}_{2}$ site. However, leucine induced extensive modification of the gene expression pattern, with the up-regulation of $A C A C A, F A D S 1, F A D S 2$ and $S C D$, and the down-regulation of FASN, CEBPA and CRAT, although these changes in mRNA levels seem to be unrelated to the fatty acid composition of adipose tissue. The mRNA expression levels of $M L X I P L$ were strongly correlated with the expression of GLUT4. It is known that the transcription factor MLXIPL is highly regulated by GLUT4 in adipose tissue, and it is a key determinant of systemic insulin sensitivity ${ }^{(15)}$. Despite the lack of differences in the mRNA levels of GLUT4 among the experimental groups, in both muscle and SAT, it is clear that the GLUT4 gene is more expressed in muscle than in SAT, thus suggesting that energy substrates are preferentially used by skeletal muscle rather than by white adipose tissue. Finally, the present results indicated a negative correlation between the expression levels of FADS2 and the percentages of $18: 2 n-6$ and PUFA in SAT.

Comparing the expression levels of genes controlling lipid metabolism in muscle and SAT, the mRNA levels of ACACA, CRAT, FABP4, FASN, LPL, PPARA, PPARG and SCD were higher in SAT than in muscle. Furthermore, the present study found a higher degree of correlation between the percentage of major fatty acids and the partial sums of fatty acids with the expression levels of key lipogenic enzymes and transcription factors in SAT than in muscle. This observation might be explained by the distinct roles of these two tissues in pig lipid metabolism. In fact, while SAT is a main site for de novo fatty acid biosynthesis and lipogenesis, muscle plays a major role in the metabolism of glucose and the degradation of lipids ${ }^{(13)}$.

\section{Conclusions}

The present study indicates that dietary arginine supplementation does not have a significant effect on IMF content in pigs, but increases total fat content in SAT without any change in back fat thickness at the $\mathrm{P}_{2}$ site. However, the gene expression analysis suggests that arginine decreases the mRNA levels of some lipogenic genes in muscle. The increased total fat content in SAT seems to be mediated by the up-regulation of the mRNA expression of FASN and SCD. Therefore, arginine might be involved in the differential regulation of some key lipogenic gene expression in pig muscle and SAT. In addition, the data confirmed that the RPD with restricted lysine levels increases the IMF content, total fat content in SAT and back fat thickness at the $\mathrm{P}_{2}$ site. Moreover, leucine supplementation of RPD does not seem to result in an additional increase of IMF, total fat in SAT or back fat thickness at the $\mathrm{P}_{2}$ site. Despite the lack of the effect of leucine supplementation on fat content, the leucine-supplemented diet increased the expression of some genes encoding for lipogenic enzymes, namely $F A S N$ and $S C D$ in muscle, and FADS1, FADS2 and SCD in SAT.

Arginine supplementation seems to affect only $n-3$ PUFA in muscle, in contrast to RPD and leucine supplementation of RPD, which changed the percentage of most of the fatty acids. The increase of MUFA content in the muscle of pigs fed the RPD and RPD with leucine supplementation seems to be cumulative due to the additional $S C D$ mRNA expression. In SAT, only the RPD seems to change the fatty acid composition, which is probably mediated by the increase in the mRNA expression of FASN and LPL.

Therefore, under the present experimental conditions, arginine supplementation of pig diets, either alone or in combination with the RPD and/or leucine, does not seem to be useful to increase the IMF content or to change the fatty acid composition of pork. In contrast, the supplementation of RPD with leucine seems to be interesting to increase MUFA content in pork. The results of the present study also indicate that adipogenesis and lipogenesis might be differently regulated in pig longissimus lumborum muscle and SAT. These data contribute to the understanding of the mechanisms of dietary regulation of fat partitioning in pigs and, therefore, could help to improve pig feeding strategies to address industry needs and consumers' demands.

\section{Acknowledgements}

The authors are grateful to Engineer J. Santos Silva and Eng. António Sequeira, from the Unidade de Investigação em Produção Animal (INIAV), for technical assistance.

We acknowledge the financial support from Fundaçãopara a Ciência e a Tecnologia (FCT) grant (PTDC/CVT/2008/ 99210) and individual fellowships to M. S. M. (SFRH/BD/ 2008/48240) and V. M. R. P. (SFRH/BPD/2009/64347). This funding contributed to the conduct of the study and the analysis of the samples.

The authors' contributions are as follows: M. S. M. and J. A. M. P. performed the animal experiment; M. S. M., V. M. R. P., 
C. M. A. and J. A. M. P. performed the tissue sampling and laboratory work, and prepared the manuscript; M. S. M., R. L., O. D., R. J. B. B. and J. A. M. P. were responsible for the interpretation of the results and preparation of the manuscript; R. J. B. B. and J. A. M. P. were responsible for the design of the study. All authors read and approved the findings of the study.

The authors declare no conflicts of interest.

\section{References}

1. Eurostat (2013) Production of meat. http://epp.eurostat.ec. europa.eu/ (accessed March 2013).

2. Wood JD, Nute GR, Richardson RI, et al. (2004) Effects of breed, diet and muscle on fat deposition and eating quality in pigs. Meat Sci 67, 651-667.

3. De Vol DL, McKeith FK, Bechtel PJ, et al. (1988) Variations in composition and palatability traits and relationships between muscle: characteristics and palatability in a random sample of pork carcasses. J Anim Sci 66, 385-395.

4. Daszkiewicz T, Bak T \& Denaburski J (2005) Quality of pork with a different intramuscular fat (IMF) content. Pol J Food Nutr Sci 14, 31-35.

5. Wood J, Enser M, Fisher A, et al. (2008) Fat deposition, fatty acid composition and meat quality: a review. Meat Sci $\mathbf{7 8}$, $343-358$.

6. Jobgen WS, Fried SK, Fu WJ, et al. (2006) Regulatory role for the arginine-nitric oxide pathway in metabolism of energy substrates. J Nutr Biochem 17, 571-588.

7. Tan B, Yin Y, Liu Z, et al. (2011) Dietary L-arginine supplementation differentially regulates expression of lipidmetabolic genes in porcine adipose tissue and skeletal muscle. J Nutr Biochem 22, 441-445.

8. Tan BE, Yin YL, Liu ZQ, et al. (2009) Dietary L-arginine supplementation increases muscle gain and reduced body fat mass in growing-finishing pigs. Amino Acids 37, 169-175.

9. Hyun Y, Kim JD, Ellis M, et al. (2007) Effect of dietary leucine and lysine levels on intramuscular fat content in finishing pigs. Can J Anim Sci 87, 303-306.

10. Hyun Y, Ellis M, Mckeith FK, et al. (2003) Effect of dietary leucine level on growth performance, and carcass and meat quality in finishing pigs. Can J Anim Sci 83, 315-318.

11. Doran O, Moule SK, Teye GA, et al. (2006) A reduced protein diet induces stearoyl-CoA desaturase protein expression in pig muscle but not in subcutaneous adipose tissue: relationship with intramuscular lipid formation. $\mathrm{Br} J \mathrm{Nutr}$ 95, 609-617.

12. Madeira MS, Pires VMR, Alfaia CM, et al. (2013) Differential effects of reduced protein diets on fatty acid composition and gene expression in muscle and subcutaneous adipose tissue of Alentejana purebred and Large White $\times$ Landrace $\times$ Pietrain crossbred pigs. Br J Nutr 110, 216-229.

13. Bergen WG \& Mersmann HJ (2005) Comparative aspects of lipid metabolism: impact on contemporary research and use of animal models. J Nutr 135, 2499-2502.

14. Zhao S, Wang J, Song X, et al. (2010) Impact of dietary protein on lipid metabolism-related gene expression in porcine adipose tissue. Nutr Metab 7, 6 .

15. Herman MA, Peroni OD, Villoria J, et al. (2012) A novel ChREBP isoform in adipose tissue regulates systemic glucose metabolism. Nature 484, 333-338.

16. Dentin R, Pégorier JP, Benhamed F, et al. (2004) Hepatic glucokinase is required for the synergistic action of ChREBP and SREBP1-1c on glycolytic and lipogenic gene expression. J Biol Chem 279, 20314-20326.
17. Liu CY, Grant AL, Kim KH, et al. (1994) Porcine somatotropin decreases acetyl-CoA carboxylase gene expression in porcine adipose tissue. Domest Anim Endocrinol 11, $125-132$.

18. Clarke SD (1993) Regulation of fatty acid synthase gene expression: an approach for reducing fat accumulation. J Anim Sci 71, 1957-1965.

19. Nakamura MT \& Nara TY (2004) Structure, function, and dietary regulation of delta6, delta5, and delta9 desaturases. Annu Rev Nutr 24, 345-376.

20. Hocquette JF, Graulet B \& Olivecrona T (1998) Lipoprotein lipase activity and mRNA levels in bovine tissues. Comp Biochem Physiol B Biochem Mol Biol 121, 201-212.

21. Hocquette JF, Gondret F, Baéza E, et al. (2010) Intramuscular fat content in meat-producing animals: development, genetic and nutritional control, and identification of putative markers. Animal 4, 303-319.

22. AOAC (2000) Official Methods of Analysis, 17th ed. Arlington, VA: AOAC.

23. Clegg KM (1956) The application of the anthrone reagent to the estimation of starch in cereals. J Sci Food Agric 70, $40-44$.

24. Sukhija PS \& Palmquist DL (1988) Rapid method for determination of total fatty acid content and composition of feedstuffs and feces. J Agric Food Chem 36, 1202-1206.

25. AOAC (2005) Official Methods of Analysis of the Association of Official Analytical Chemists International, 18th ed, p. 473 [GW Latimer and W Horwitz, editors]. Gaithersburg, MD: AOAC International.

26. Henderson JW, Ricker RD, Bidlingmeyer BA, et al. (2000) Rapid, Accurate, Sensitive and Reproducible Analysis of Amino Acids. Palo Alto, CA: Agilent Technologies (Agilent Publication No. 5980-1193EN).

27. Folch J, Lees M, Sloane Stanley GH, et al. (1957) A simple method for the isolation and purification of total lipides from animal tissues. J Biol Chem 226, 497-509.

28. Carlson LA (1985) Extraction of lipids from human whole serum and lipoproteins and from rat liver tissue with methylene chloride-methanol: a comparison with extraction chloroform-methanol. Clin Chim Acta 149, 89-93.

29. Raes K, De Smet SD \& Demeyer D (2001) Effect of double-muscling in Belgian Blue young bulls on the intramuscular fatty acid composition with emphasis on conjugated linoleic acid and polyunsaturated fatty acids. Anim Sci 73, 253-260.

30. Vandesompele J, De Preter K, Pattyn F, et al. (2002) Accurate normalization of real-time quantitative RT-PCR data by geometric averaging of multiple internal control genes. Genome Biol 3, 7.

31. Andersen CL, Jensen JL \& Orntoft TF (2004) Normalization of real-time quantitative reverse transcription-PCR data: a model-based variance estimation approach to identify genes suited for normalization, applied to bladder and colon cancer data sets. Cancer Res 64, 5245-5250.

32. Livak KJ \& Schmittgen TD (2001) Analysis of relative gene expression data using real-time quantitative PCR and the 2(-Delta $C(T)$ ) method. Methods 25, 402-408.

33. Fleige S, Walf V, Huch S, et al. (2006) Comparison of relative mRNA quantification models and the impact of RNA integrity in quantitative real-time RT-PCR. Biotechnol Lett 28, 1601-1613.

34. SAS Institute, Inc. (2009) SAS/STAT 9.2 User's Guide, 2nd ed. Cary, NC: SAS Institute, Inc. 
35. Milliken GA \& Johnson DE (2002) Analysis of Messy Data, Volume III: Analysis of Covariance. London: Chapman and Hall/CRC.

36. Alonso V, Campo MDM, Provincal L, et al. (2010) Effect of protein level in commercial diets on pork meat quality. Meat Sci 85, 7-14.

37. Ma X, Lin Y, Jiang Z, et al. (2010) Dietary arginine supplementation enhances antioxidative capacity and improves meat quality of finishing pigs. Amino Acids 38, 95-102.

38. Cisneros R, Ellis M, Baker DH, et al. (1996) The influence of short-term feeding of amino-acid deficient diets and high dietary leucine levels on the intramuscular fat content of pig muscle. Anim Sci 63, 517-522.

39. Go G, Wu G, Silvey DT, et al. (2012) Lipid metabolism in pigs fed supplemented conjugated linoleic acid and/or dietary arginine. Amino Acids 43, 1713-1726.

40. Glaser C, Heinrich J \& Koletzko B (2010) Role of FADS1 and FADS2 polymorphisms in polyunsaturated fatty acid metabolism. Metab Clin Exp 59, 993-999.
41. Hagen RM, Rodriguez-Cuenca S \& Vidal-Puig A (2010) An allostatic control of membrane lipid composition by SREBP1. FEBS Lett 584, 2689-2698.

42. Dubuquoy C, Robichon C, Lasnier F, et al. (2011) Distinct regulation of adiponutrin/PNPLA3 gene expression by the transcription factors ChREBP and SREBP1c in mouse and human hepatocytes. J Hepatology 55, 145-153.

43. Michal JJ, Zhang ZW, Gaskins CT, et al. (2006) The bovine fatty acid binding protein 4 gene is significantly associated with marbling and subcutaneous fat depth in Wagyu $X$ Limousin F2 crosses. Anim Genet 37, 400-402.

44. Fu WJ, Haynes TE, Kohli R, et al. (2005) Dietary L-arginine supplementation reduces fat mass in Zucker diabetic fatty rats. J Nutr 135, 714-721.

45. Fouad AM, El-Senousey HK, Yang XJ, et al. (2013) Dietary L-arginine supplementation reduced abdominal fat content by modulating lipid metabolism in broiler chickens. Animal 7, 1239-1245. 